\title{
Dynamic Cooling Effects of Permanent Urban Green Spaces in Beijing, China
}

\author{
Jiacheng Zhao ${ }^{1,2} \mathbb{D}$, Xiang Zhao ${ }^{1,2, * \mathbb{C}}$, Shunlin Liang ${ }^{3}{ }^{\mathbb{D}}$, Haoyu Wang ${ }^{4}$, Naijing Liu ${ }^{1,2}$, Ping Liu ${ }^{5}$ and \\ Donghai $\mathrm{Wu}^{6}{ }^{6}$
}

check for updates

Citation: Zhao, J.; Zhao, X.; Liang, S.; Wang, H.; Liu, N.; Liu, P.; Wu, D.

Dynamic Cooling Effects of Permanent Urban Green Spaces in Beijing, China. Remote Sens. 2021, 13, 3282. https://doi.org/10.3390/ rs13163282

Academic Editor: Jagannath Aryal

Received: 8 July 2021

Accepted: 16 August 2021

Published: 19 August 2021

Publisher's Note: MDPI stays neutral with regard to jurisdictional claims in published maps and institutional affiliations.

Copyright: (c) 2021 by the authors. Licensee MDPI, Basel, Switzerland. This article is an open access article distributed under the terms and conditions of the Creative Commons Attribution (CC BY) license (https:// creativecommons.org/licenses/by/ $4.0 /)$.
1 State Key Laboratory of Remote Sensing Science, Jointly Sponsored by Beijing Normal University and Aerospace Information Research Institute of Chinese Academy of Sciences, Faculty of Geographical Science, Beijing Normal University, Beijing 100875, China; zhaojiacheng@mail.bnu.edu.cn (J.Z.); liunj@mail.bnu.edu.cn (N.L.)

2 Beijing Engineering Research Center for Global Land Remote Sensing Products, Institute of Remote Sensing Science and Engineering, Faculty of Geographical Science, Beijing Normal University, Beijing 100875, China

3 Department of Geographical Sciences, University of Maryland, College Park, MD 20742, USA; sliang@umd.edu

4 School of Earth and Space Sciences, Peking University, Beijing 100871, China; why0925@stu.pku.edu.cn

5 College of Data Science, Taiyuan University of Technology, Taiyuan 030024, China; liuping01@tyut.edu.cn

6 Department of Ecology and Evolutionary Biology, Cornell University, Ithaca, NY 14853, USA; dw623@cornell.edu

* Correspondence: zhaoxiang@bnu.edu.cn

\begin{abstract}
Urban green spaces (UGSs) play a critical role in human thermal comfort, energy consumption and urban ecology. Although the heat mitigation capability of UGSs has been frequently reported, many of the current understandings are based on short-term observations, and the long-term temporal dynamics of UGS cooling effects are still lacking. This gap may cause over- or underestimation and largely ignores how the cooling effects change with climate change and urban growth. Accordingly, we used Landsat-based time series data to analyze the changes in permanent UGS greenness, surface-cooling effects and their biophysical responses in Beijing in the past 40 years (1984-2020). The results demonstrate segmented changes in UGS surface cooling that were mainly linked to the responses of canopy transpiration and albedo to vegetation conditions. During a rapid greening of UGSs in the recent two decades, transpiration cooling dominated albedo-induced warming to provide a discernable cooling enhancement. In addition, such enhancement showed seasonal differences ranging from less than $1^{\circ} \mathrm{C}$ to more than $2{ }^{\circ} \mathrm{C}$, and the most evident enhancement occurred on summer days $\left(\sim 2.4^{\circ} \mathrm{C}\right)$ when vegetation is most needed to provide cooling. The highlighted dynamics of UGSs help urban planners better balance the maintenance costs and the environmental gains for UGS management.
\end{abstract}

Keywords: urban green spaces; dynamic monitoring; surface cooling; urban climate; Beijing

\section{Introduction}

Urban green spaces (UGSs) are defined as vegetated open spaces in urban areas [1]. They improve environmental sustainability and residents' well-being in multiple ways. For instance, UGSs play an essential role in maintaining high levels of urban biodiversity [2]. They also reduce air pollutants and mitigate urban floods [3,4]. Additionally, UGSs facilitate people's mental health and reduce mortality by providing elevated exposure to nature, which helps alleviate stress and enhance physical activity [5,6]. Another major function of UGSs is climate mitigation. It is well known that UGSs reduce urban heat through both shading and transpiration. A large tree canopy with dense leaves forms solid shadows that prevent heating from solar radiation, while the process of transpiration consumes this solar energy to evaporate liquid water from leaves to the atmosphere, consequently reducing both the leaf surface temperature and surrounding air temperature [7]. This cooling effect of 
UGSs will be increasingly important in future urban development, since urban areas have been projected to experience more serious warming than regional background warming [8].

There are currently three main methods used to measure UGS cooling effects. First, tree-level field measurements are conducted for various species to find potential drivers (such as leaf area index (LAI), canopy geometry, stress tolerance, microclimate factors and growing conditions) that affect the cooling efficiency [9-11]. Second, remotely sensed images at the city scale are widely utilized to map UGSs [12] and explore the relationship between UGS cooling intensity/distance and their bio and geometric features [13-15]. The cooling intensity is defined as the thermal difference between the UGS and its surroundings [16], while the cooling distance measures the spatial extent beyond which the UGS ceases to provide local cooling effects [17]. Third, the cooling effects at the neighborhood scale are estimated by mechanistic models, which consider street scenarios with different planting patterns and urban morphologies [18,19]. Despite the remarkable contributions of these studies, most of them were conducted during a single period (from a few months [20] to a few years [11]), and the long-term temporal dynamics of permanent UGS cooling effects have rarely been reported. In drylands, plant physiology is tightly linked to changes in precipitation and frequency [21,22]. For plants in dry cities, their physiological traits could be more variable due to the need for human management and irrigation [23]. Consequently, changes in vegetation greenness (e.g., greening or browning) alter land-atmosphere interactions through biophysical processes, and the cooling effects are therefore modified over time. For instance, a field campaign conducted in a semiarid shrub ecosystem observed that deep-soil moisture led to an increase in LAI and a decrease in canopy albedo [24]. In this process, a higher LAI increases canopy transpiration to result in more cooling effects, while a lower albedo absorbs more solar energy to cause warming effects. Finally, the two biophysical responses collectively determine the change in vegetation thermal effects [25].

Remote sensing techniques intrinsically have advantages in land surface monitoring due to satellite repeatability. Landsat sensors have circled the Earth since 1972, providing the longest and richest continuous satellite observations. With a spatial resolution of $30 \mathrm{~m}$, Landsat images are capable of featuring finer-scale anthropogenic impacts and detailed UGS (e.g., parks, urban forests, street trees, lawns) characteristics and are thus widely used for UGS monitoring and modeling $[15,26,27]$. Landsat time series data provide more dynamic and comprehensive land processes than bitemporal image comparisons and capture abrupt, stochastic events, as well as subtle changes, over long periods [28]. Hence, the data are well suited for the long-term monitoring of UGSs and can be used to report how UGSs grow, decline and potentially change with urbanization and management.

Based on Landsat-based observations, this study performed time series analyses (19842020) on permanent UGSs in Beijing, a typical semiarid metropolis located in northern China. Seasonal cycles and stochastic noise were removed to extract the trends of various surface parameters, including the vegetation index, land surface temperature (LST), evapotranspiration (ET) and albedo. We also applied segmented regressions to time series data to find potential breakpoints. In general, we aimed to explore the dynamics of permanent UGSs and the changes in their environmental benefits by answering the following questions: (i) did the greenness of these UGSs change over the past 40 years, and when did the changes happen?; (ii) did these changes provide variant cooling effects?; and (iii) how do vegetation physiological processes account for these changing cooling effects?

\section{Materials and Methods}

\subsection{Study Area}

Beijing is one of the leading metropolises in China and has over 3000 years of history. As of 2018, there were more than 21 million people who resided in Beijing. The city is located on the North China Plain between $39^{\circ} 28^{\prime}-41^{\circ} 05^{\prime} \mathrm{N}$ and $115^{\circ} 25^{\prime}-117^{\circ} 30^{\prime} \mathrm{E}$, experiencing a warm temperate semiarid continental monsoon climate that features four distinct seasons. The city has an annually averaged daily temperature of $10-12{ }^{\circ} \mathrm{C}$, with monthly mean values varying between $-5{ }^{\circ} \mathrm{C}$ and $30{ }^{\circ} \mathrm{C}$. The annual precipitation in Beijing is 
approximately $650 \mathrm{~mm}$, which mostly occurs in July and August. The growing season typically starts in April and lasts until the end of October.

The study was carried out in permanent UGSs in Beijing located within the 4th Ring Road (Figure 1). These UGSs were identified from the Chinese urban park dataset by $\mathrm{Li}$ et al. [29] and the Google historical images. We selected the UGSs that cover at least 100 Landsat pixels (approximately equal to 10 ha) because too small UGSs are easily affected by their surroundings and thus raise uncertainty. Formed before 1949, most of these UGSs are famous historical parks, e.g., North Lake Park and Coal Hill Park, consisting of abundant arbors, shrubs, herbaceous species and water bodies [30]. Due to their outstanding historical and cultural values, both landscape patterns and garden elements are well protected. Thus, these permanent UGSs provide us with a suitable testbed to quantify the long-term cooling dynamics of urban vegetation.

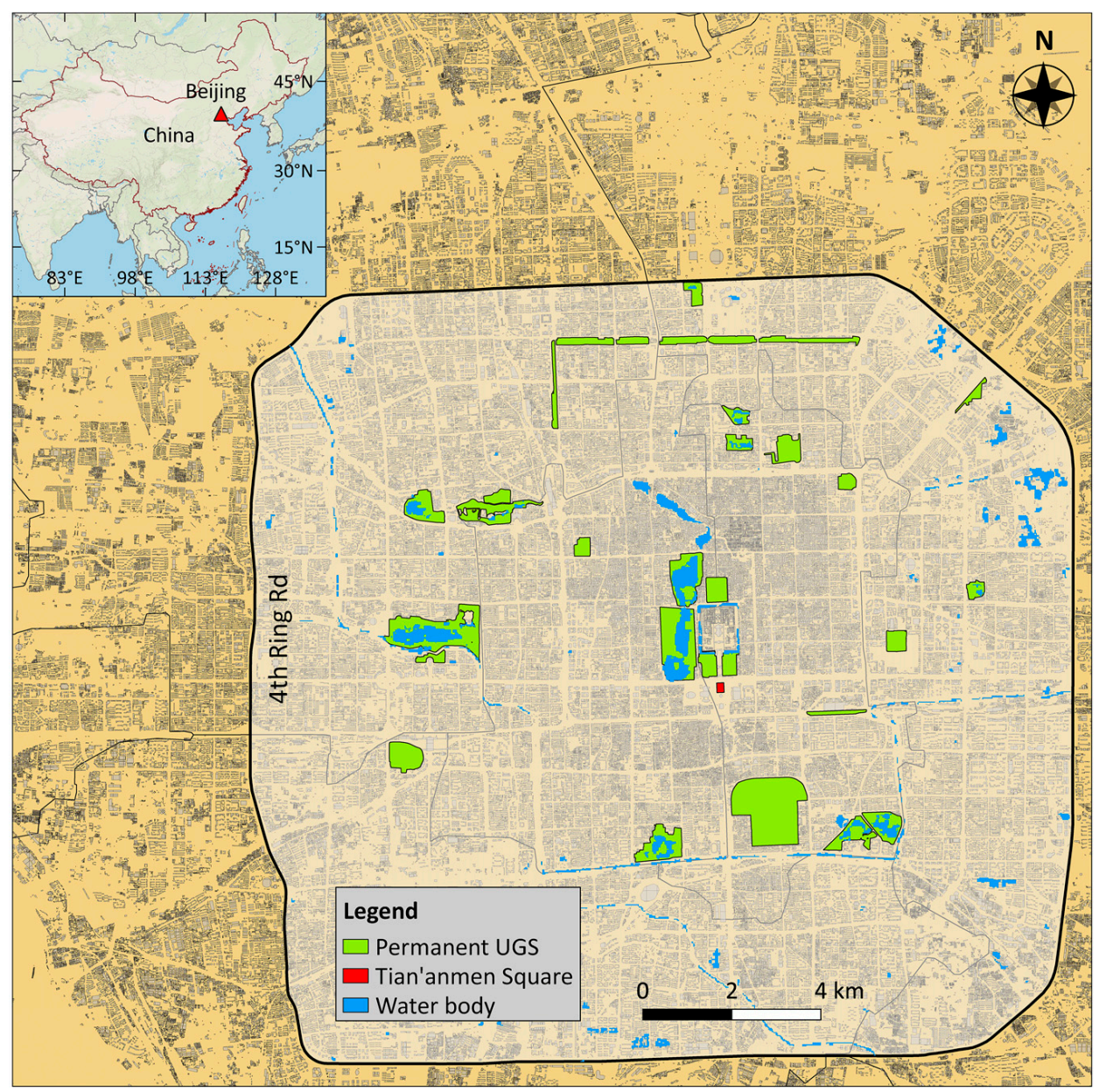

Figure 1. Geographic map of the study area. Outlined permanent urban green spaces (UGSs) with an area greater than 10 ha are located in the Beijing main city within the 4th Ring Road.

\subsection{Overall Workflow}

Figure 2 illustrates the overall workflow of the study. We first combined Landsat 5 and Landsat 8 surface reflectance datasets to form a long-term time series from 1984 to 2020. Next, based on the dataset, we retrieved four surface parameters including the normalized difference vegetation index (NDVI), LST, ET and albedo using different algorithms. Finally, we analyzed the greenness and cooling dynamics of UGSs and their biophysical responses using time series tools. Detailed descriptions of these steps are shown in the following sections. 


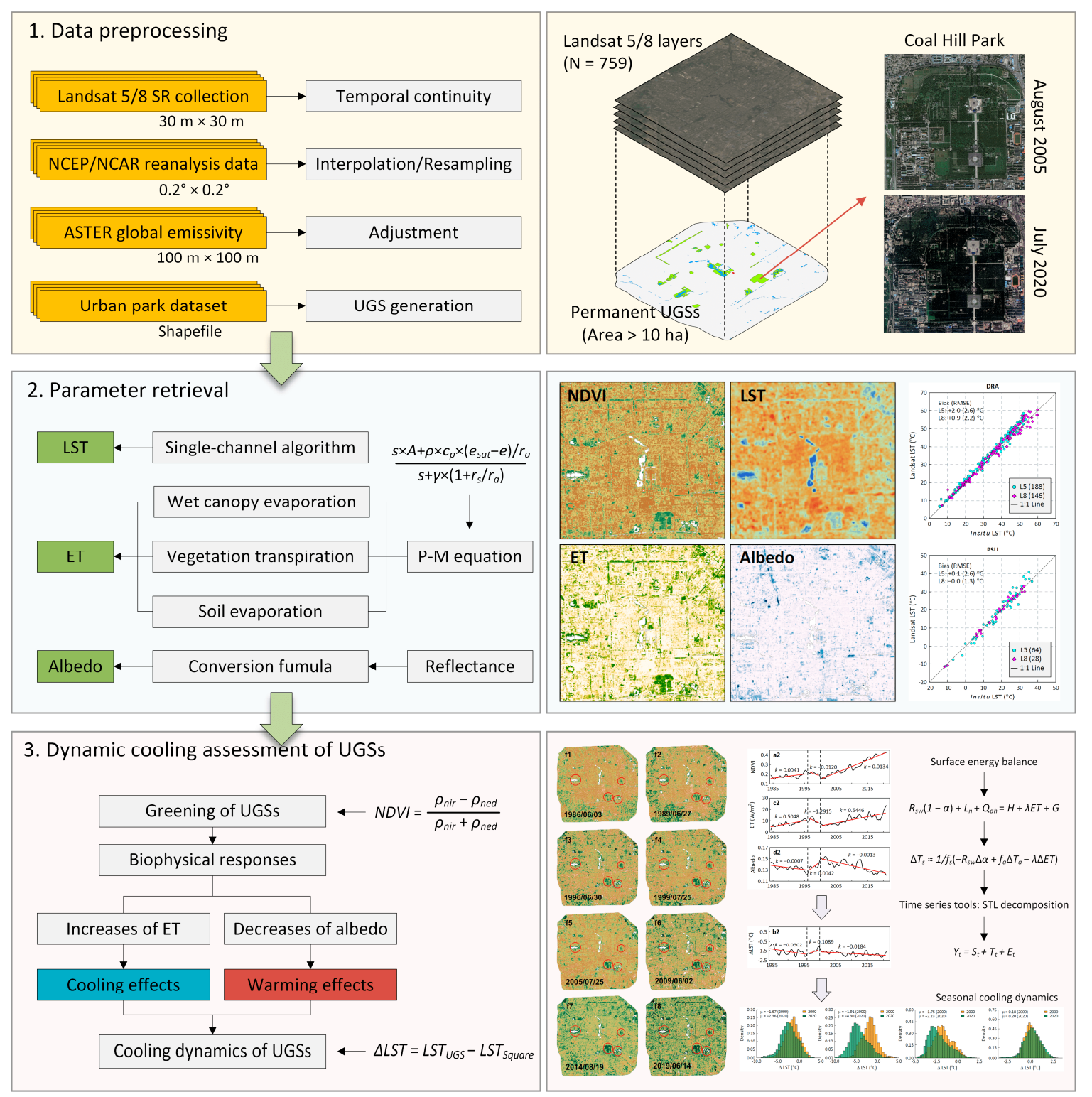

Figure 2. Overall workflow of the study. The main steps consist of data preprocessing, parameter retrieval and dynamic cooling assessment of UGSs. Note that SR refers to surface reflectance.

\subsection{Landsat Surface Reflectance Collection}

With a 16-day revisit cycle, the Landsat images provide long, continuous and global records of the Earth's surface at a mesoscale $(30 \mathrm{~m} \times 30 \mathrm{~m})$. In this study, we used atmospherically corrected Landsat $5 / 8$ surface reflectance images covering our study area from 1984 to 2020, which are freely available on the Google Earth Engine (GEE) cloud platform [31]. For Landsat 5, atmospheric distortion is corrected using the Landsat Ecosystem Disturbance Adaptive Processing System (LEDAPS) algorithm [32], while for Landsat 8, atmospheric effects are eliminated using the Land Surface Reflectance Code (LaSRC, [33]). These images consist of visible, near-infrared and shortwave-infrared bands processed to orthorectified surface reflectance and thermal infrared bands processed to orthorectified brightness temperature. For each image, cloud and cloud shadows were masked based on the CFMASK algorithm [34]. We excluded images in which none of the UGSs could be seen. Landsat 7 images were not used because of the data gaps caused by the failure of the scan-line corrector. These processes finally gave us 287 Landsat 5 
(1984-2012) and 103 Landsat 8 (2013-2020) images (Figure 3). The image metadata is given in Appendix A.

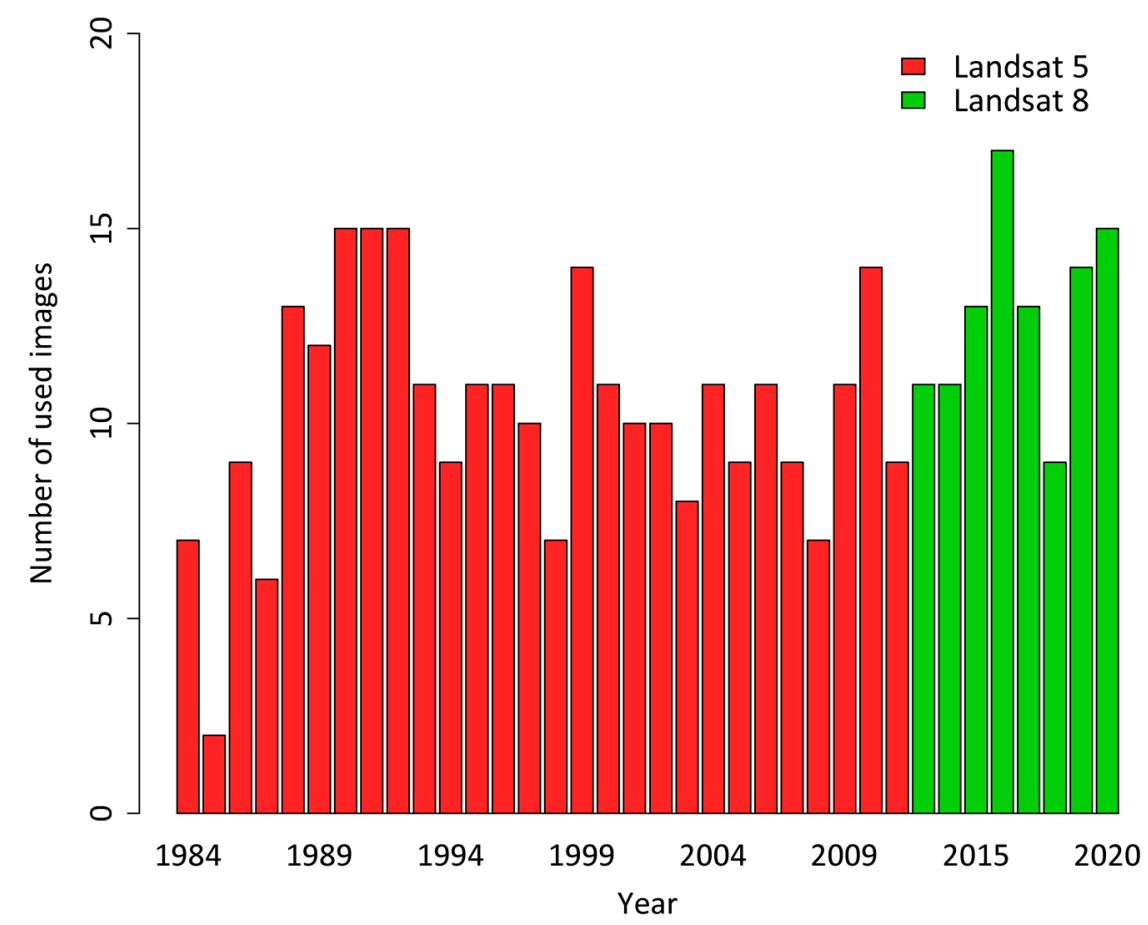

Figure 3. Number of Landsat images used for each year from 1984 to 2020. A total of 390 (287 of Landsat 5 and 103 of Landsat 8) images were used.

Directly combining Landsat 8 data with those from previous Landsat sensors is not suitable for long-term dynamic monitoring and trend analysis because Landsat 8 OLI/TIRS has spectrally narrower bands than those of previous Landsat sensors [35]. To improve the temporal continuity of the Landsat 8 data, we adjusted the surface reflectance of visible (blue, green, red), near-infrared and two shortwave bands of each Landsat 8 image to be compatible with Landsat 5 surface reflectance by using Roy's between-sensor transformation functions [36] as follows:

$$
\rho_{\text {adj }}=\left\{\begin{array}{cc}
0.0183+0.8850 \rho, & \text { Blue } \\
0.0123+0.9317 \rho, & \text { Green } \\
0.0123+0.9372 \rho, & \text { Red } \\
0.0448+0.8339 \rho, & \text { Near infrared } \\
0.0306+0.8639 \rho, & \text { Shortwave infrared } 1 \\
0.0116+0.9165 \rho, & \text { Shortwave infrared } 2
\end{array}\right.
$$

where $\rho$ is the surface reflectance of Landsat 8 bands and $\rho_{a d j}$ is adjusted surface reflectance. The functions are derived using the ordinary least squares (OLS) regression from almost 60 million $30 \mathrm{~m}$ common pixel values extracted from more than 6000 Landsat 7 ETM+ and Landsat 8 OLI overlapped images acquired over three winter and three summer months for all the conterminous United States [36]. Other applications of the functions to long time series analyses of vegetation in the Tibetan Plateau [37] and Hindu Kush Himalaya [38] further indicate their universality. 


\subsection{Landsat-Based Surface Parameter Retrieval}

\subsubsection{Normalized Difference Vegetation Index}

We employed the most widely used vegetation index, i.e., NDVI, to quantify vegetation greenness, density and conditions. NDVI is computed as the difference between the reflectance of the near-infrared and red bands, divided by their sum as follows:

$$
\mathrm{NDVI}=\frac{\rho_{\text {nir }}-\rho_{\text {red }}}{\rho_{\text {nir }}+\rho_{\text {red }}}
$$

\subsubsection{Land Surface Temperature}

We employed a generalized single-channel algorithm [39] to retrieve LST from atsensor brightness temperature using the following equations:

$$
T_{s}=\gamma\left[\mathcal{E}^{-1}\left(\psi_{1} L_{s e n}+\psi_{2}\right)+\psi_{3}\right]+\delta
$$

with

$$
\begin{gathered}
\gamma=\left\{\frac{c_{2} L_{\text {sen }}}{T_{\text {sen }}^{2}}\left[\frac{\lambda^{4}}{c_{1}} L_{\text {sen }}+\lambda^{-1}\right]\right\}^{-1} \\
\delta=-\gamma L_{\text {sen }}+T_{\text {sen }}
\end{gathered}
$$

where $\varepsilon$ is the surface emissivity that is first spectrally adjusted from the Advanced Spaceborne Thermal Emission and Reflection Radiometer (ASTER) global emissivity dataset and then modified for vegetation phenology and snow-cover changes following the procedures given by Malakar et al. [40]; $L_{s e n}$ is the at-sensor radiance converted from raw Landsat digital numbers (DNs); $T_{s e n}$ is the brightness temperature; $\lambda$ is the effective wavelength; $c_{1}$ and $c_{2}$ are Planck's radiation constants; and $\psi_{1}, \psi_{2}$ and $\psi_{3}$ are the atmospheric functions of total atmospheric water vapor content $(w)$, given by the following:

$$
\left[\begin{array}{l}
\psi_{1} \\
\psi_{2} \\
\psi_{3}
\end{array}\right]=\left[\begin{array}{lll}
c_{11} & c_{12} & c_{13} \\
c_{21} & c_{22} & c_{23} \\
c_{31} & c_{32} & c_{33}
\end{array}\right]\left[\begin{array}{c}
w^{2} \\
w \\
1
\end{array}\right]
$$

where $c_{i j}$ values are fitted using atmospheric sounding databases for different Landsat sensors [41].

The total atmospheric water vapor content was extracted from the Moderate Resolution Imaging Spectroradiometer (MODIS) combined multiangle implementation of atmospheric correction (MAIAC) land aerosol optical depth (AOD) gridded Level 2 product (MCD19A2) with a spatial resolution of $1 \mathrm{~km}$ [42]. Because the dataset is available after 2000, we used the water vapor from the National Centers for Environmental Prediction (NCEP) and National Center for Atmospheric Research (NCAR) reanalysis data as an alternative before 2000. When the MODIS water vapor was masked due to cloud contamination, the NCEP/NCAR data were used. The NCEP/NCAR water vapor has a 6-h temporal resolution (00:00, 06:00, 12:00 and 18:00 UTC) and 2.5-degree spatial resolution [43]. The water vapor at each Landsat acquisition time was approximated by linearly interpolating the two closest water vapor values [44].

We validated the retrieved LST with cloud cover less than 30\% using in situ measurements of six surface radiation budget (SURFRAD) stations in the United States (Figure 4). The stations primarily record the downwelling and upwelling components of broadband solar radiation and thermal infrared irradiance in 3 min intervals before January 2009 and every minute thereafter. The data are quality controlled and cover multiple land cover types (e.g., vegetation, grassland and cropland) in diverse climates [40]. The measurements used to validate LST were from 1995-2020. To minimize the uncertainty caused by spatial heterogeneity, we removed the Landsat LSTs that had a standard deviation of $3 \times 3$ pixels surrounding the station larger than $1{ }^{\circ} \mathrm{C}$ [40]. We also removed potential outliers based

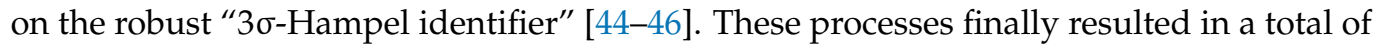


1468 Landsat observations that were matched with those of SURFRAD for the closest time. The overall biases (root mean square error) for Landsat 5 and Landsat 8 were $1.0^{\circ} \mathrm{C}$ and $0.6^{\circ} \mathrm{C}$, respectively.
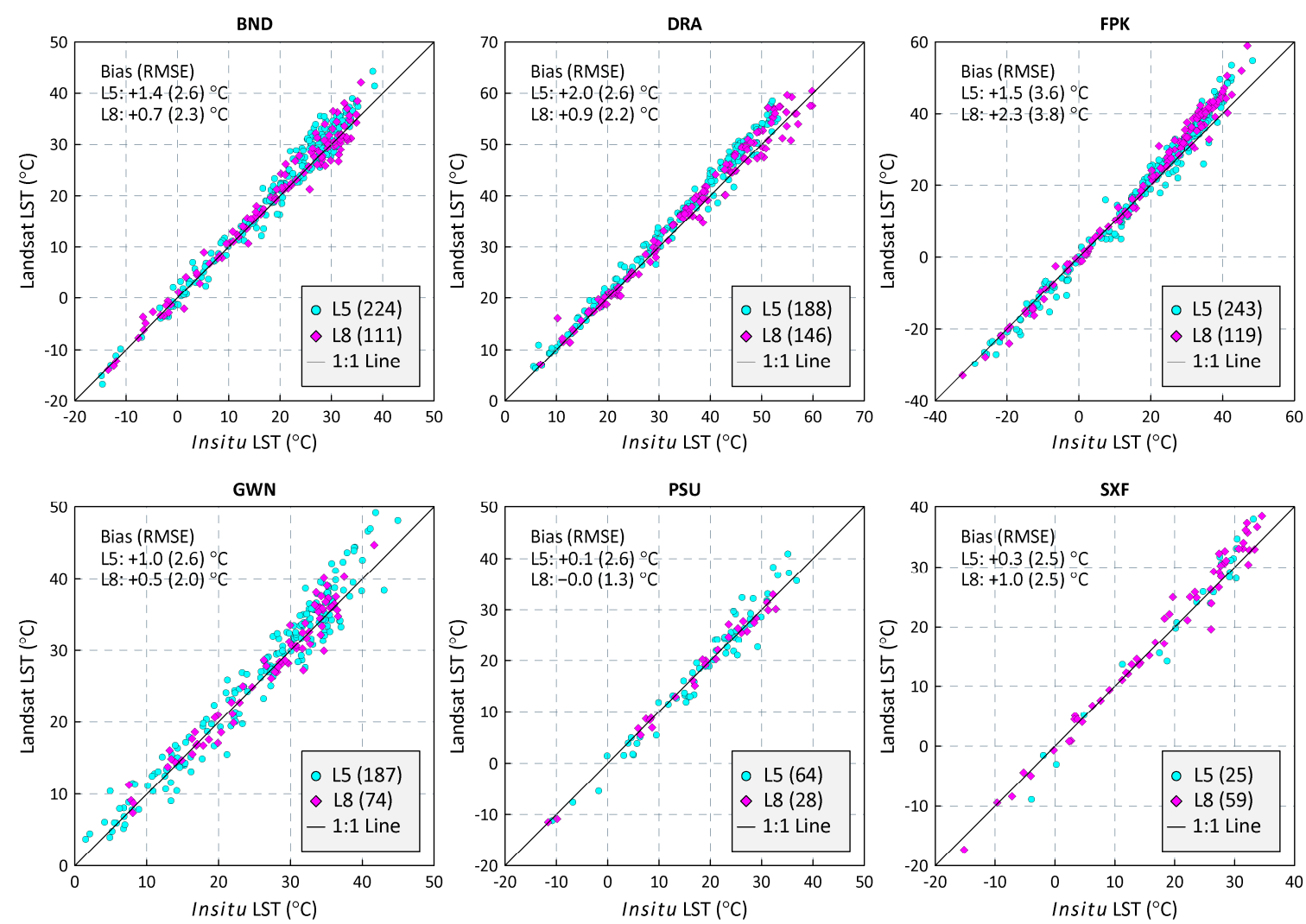

Figure 4. Scatterplots of Landsat-retrieved land surface temperature (LST) versus in situ LST at six SURFRAD stations (i.e., Bondville, Illinois (BND); Desert Rock, Nevada (DRA); Fort Peck, Montana (FPK); Goodwin Creek, Mississippi (GWN); Penn. State Univ., Pennsylvania (PSU); and Sioux Falls, South Dakota (SXF)). Parentheses in each figure legend indicate the number of observations used for validation. The data are from the years 1995-2020.

\subsubsection{Evapotranspiration}

We transferred the MODIS terrestrial ET algorithm [47] to retrieve fine-resolution ET by using the Landsat-based fractional vegetation cover. The algorithm is based on the Penman-Monteith equation [48]:

$$
\mathrm{ET}=\frac{s \times A+\rho \times c_{p} \times\left(e_{s a t}-e\right) / r_{a}}{s+\gamma \times\left(1+r_{s} / r_{a}\right)}
$$

where $s$ is the slope of the saturation water vapor pressure curve; $A$ is the available energy partitioned between sensible heat, latent heat and soil heat fluxes on the land surface; $\rho$ is the mean air density at constant pressure; $c_{p}$ is the specific heat of the air; $e_{s a t}$ is the saturation vapor pressure; $e$ is the actual water vapor pressure; $e_{s a t}-e$ represents the vapor pressure deficit of the air; $\gamma$ is the psychometric constant and $r_{a}$ and $r_{s}$ are the aerodynamic and surface resistance, respectively. The derivation of these inputs requires climate variables such as daily surface net radiation, air temperature and relative humidity, which were extracted from the NCEP climate forecast system version 2 (CFSv2) 6-h products [49].

Then, the total daily ET is the sum of the evaporation from the wet canopy surface, vegetation transpiration and evaporation from the soil surface calculated from Equation (7). When the relative humidity is less than $70 \%$, the surface is assumed to be not covered by 
water, and the wet canopy surface evaporation and soil surface evaporation are then zero. A detailed calculation of these components can be found in [47].

In the MODIS algorithm, parameters that affect stomatal conductance, such as the mean potential stomatal conductance per unit leaf area, were parameterized globally using 46 AmeriFlux tower-based ET for 11 different biomes, i.e., evergreen needleleaf forest; evergreen broadleaf forest; deciduous needleleaf forest; deciduous broadleaf forest; mixed forest; woody savannas; savannas; closed shrubland; open shrubland; grassland, urban and built-up land; barren or sparsely vegetated land; and cropland. To determine which set of these parameters should be used for the UGSs in the study, we merged a high-resolution $(100 \mathrm{~m})$ land-cover scheme from the Copernicus global land-cover layers [50] in 2015 to correspond to the 11 biomes above. The land cover types of the permanent UGSs in this study are assumed to be unchanged during the study period.

\subsubsection{Albedo}

We converted narrowband surface reflectance to broadband albedo in total shortwave using the formula given by Liang [51] as follows:

$$
\alpha_{\text {short }}=0.356 \alpha_{1}+0.130 \alpha_{3}+0.373 \alpha_{4}+0.085 \alpha_{5}+0.072 \alpha_{7}-0.0018
$$

where $\alpha_{1}, \alpha_{3}, \alpha_{4}, \alpha_{5}$ and $\alpha_{7}$ are the narrowband surface reflectance of the Landsat blue band, red band, near-infrared band, shortwave-infrared band 1 and shortwave-infrared band 2 , respectively. The MODIS daily albedo product (MCD43A3) was successfully used for change detection [52] and thus we employed it to help detect the albedo dynamics of UGSs.

\subsection{Surface-Cooling Dynamics and Time Series Analysis}

The surface-cooling effects of UGSs at time $t$ are defined as the LST difference between UGSs and Tian'anmen Square (Figure 1), namely,

$$
\Delta L S T_{t}=L S T_{t}^{U G S}-L S T_{t}^{\text {Square }}
$$

Tian'anmen Square was chosen as a typical urban impervious surface for comparison because of its homogeneity and invariance since 1954. Given this, a negative $\Delta L S T$ indicates that the surface temperature of UGSs is lower than that of urban impervious surfaces; therefore, they represent cooling effects and smaller values suggest stronger cooling.

To detect and explain the dynamic cooling effects of UGSs, we first generated four time series for the NDVI, $\triangle L S T$, ET and albedo of the selected permanent UGSs (Figure 1) from 1984-2020. Then, we imputed the missing data (due to the removal of cloudy images) of each time series by using the seasonal Kalman filter and deconstructed the four completed time series into an additive seasonal component $\left(S_{t}\right)$, trend component $\left(T_{t}\right)$ and residual component $\left(E_{t}\right)$ using a locally weighted regression smoother (LOESS) [53], as follows:

$$
Y_{t}=S_{t}+T_{t}+E_{t}
$$

where the seasonal component represents the vegetation phenology cycle, and the trend component detects the temporal vegetation dynamics. Hereafter, we implemented an iterative procedure of linear fitting [54] on the four trend series to examine potential breakpoints and whether segmented relationships existed in the time series.

\section{Results}

\subsection{Greenness Dynamics}

Based on the reconstructed Landsat NDVI time series from 1984 to 2020 (Figure 5b), we extracted the NDVI trend of UGSs and observed overall greening (Figure 5d). In 1986, even in the growing seasons, UGSs were in poor condition with a very low NDVI of approximately 0.2 (Figure $5 b$ ), and they were hardly distinguished from non-vegetated areas (Figure 5f1). By 2020, however, the annual UGS NDVI had risen to 0.4 (Figure 5d), 
with the growing season NDVI reaching 0.5 (Figure $5 b$ ). Such changes were achieved through three segmented relationships before 1996, during 1996-2000 and after 2000. Before 1996, the NDVI slowly increased at a rate of +0.004 /year After 1996, however, the UGSs experienced short-term deforestation (with an NDVI decrease rate of -0.012 /year) until 2000, reducing their greenness almost back to the level of 1984. Hereafter, UGSs rapidly grew with a sharply increased NDVI rate of +0.013 /year, which was particularly true for large UGSs (circled in Figure 5f).
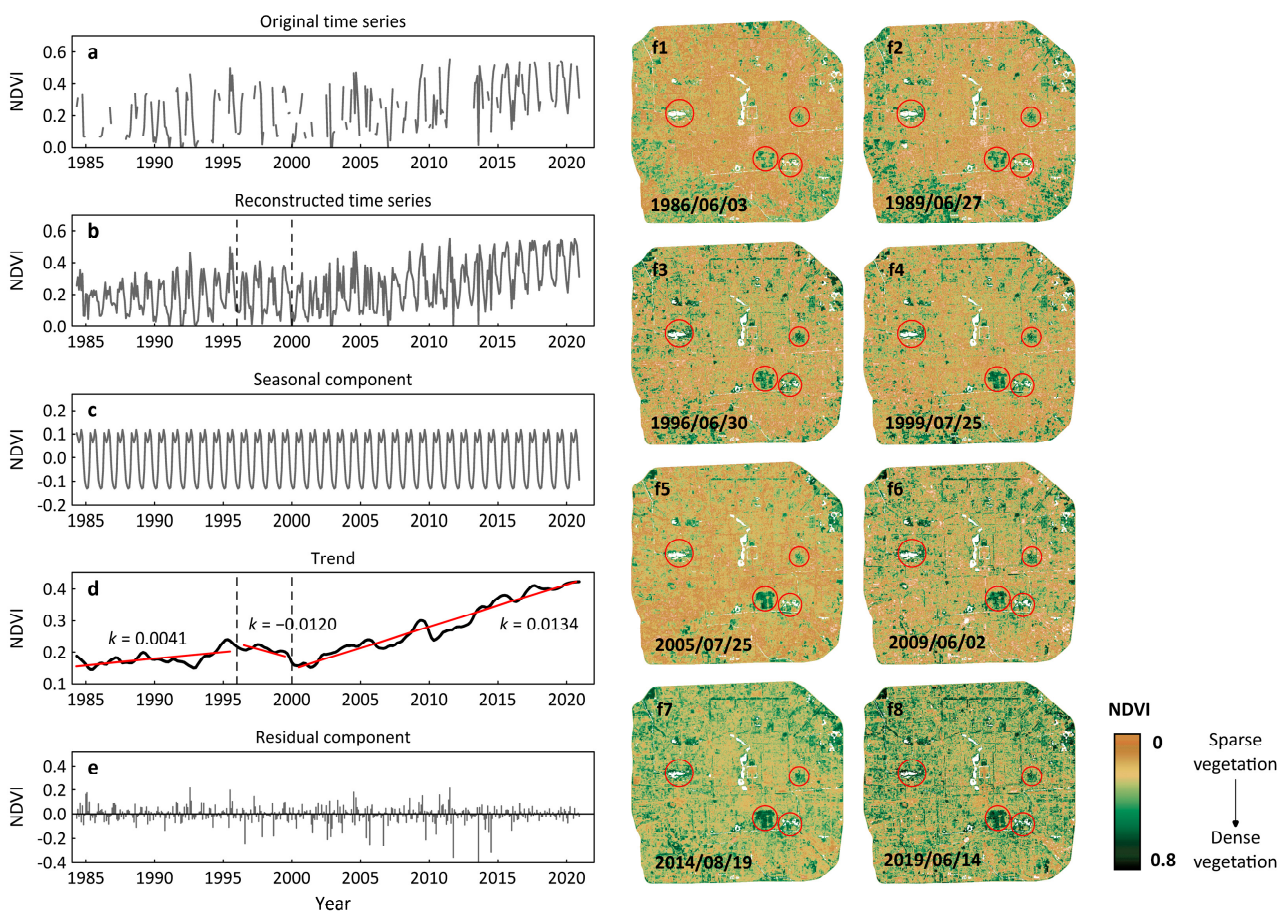

Figure 5. Dynamics of UGS greenness. The figures in the left panel are (a) the original normalized difference vegetation index (NDVI) time series, (b) reconstructed NDVI time series, (c) seasonal component of the NDVI, (d) extracted trend of the NDVI and (e) residual component. Each NDVI value is averaged from all pixels of the UGSs (Figure 1). The dashed lines indicate the breakpoints (1996 and 2000, respectively). The figures in the right panel (f1-f8) are NDVI images in the growing seasons (April to October) approximately every five years since 1984.

\subsection{Responses of Urban Green Space Surface Cooling to Greening}

By comparing the temporal LST difference ( $\triangle L S T)$ between UGSs and Tian'anmen Square (a typical permanent impervious surface in Beijing, Figure 1), we observed a positive response of most UGS daytime surface-cooling effects $(\triangle L S T)$ to their greenness (Figures 5 and 6). UGS greening (before 1996 and after 2000) led to cooling enhancements, while their browning (during 1996-2000, Figure 5d) resulted in cooling attenuation (Figure 6c). The overall cooling enhancement made UGSs recently experience an approximately $2{ }^{\circ} \mathrm{C}$ lower annual surface temperature than impervious surfaces compared to the value of no more than $1.5^{\circ} \mathrm{C}$ in 1984 (Figure 6c). A spatial comparison of this cooling enhancement was illustrated by using the $\triangle L S T$ image composites from 2000 and 2020. This is because 2000 was a trough representing poor vegetation performance, which could be sharply compared with 2020, when the vegetation condition had grown to its peak. In contrast with 1984, 2000 also had sufficient images to make an annual composite (Figure 6a). Spatially, almost all UGSs experienced a distinctly lower LST in 2020 (Figure 6e), which was true only for approximately half of the UGSs in 2000 (Figure 6d). 


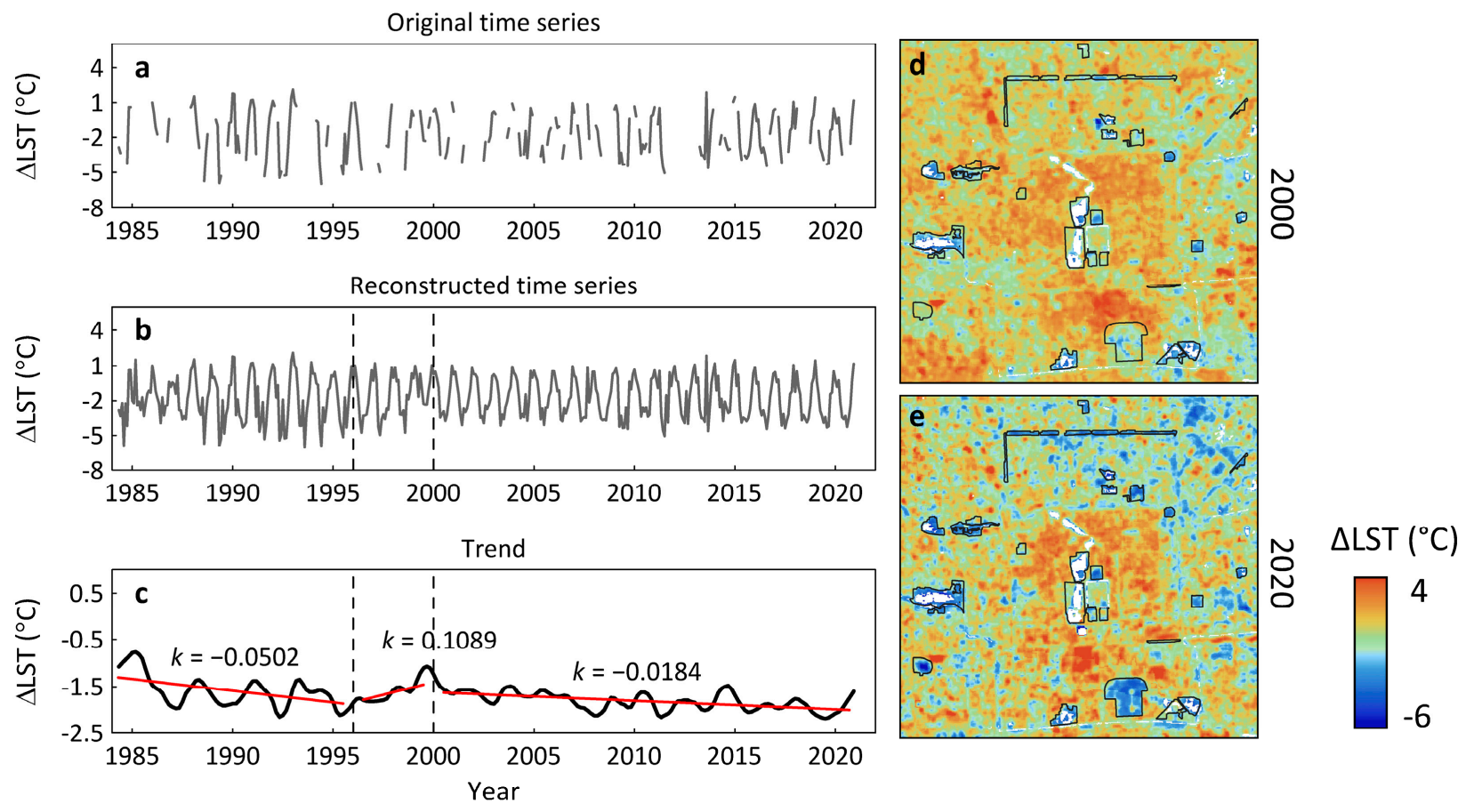

Figure 6. Dynamics of UGS daytime surface cooling. The figures in the left panel are (a) the original $\Delta L S T$ (defined as the LST difference between the UGSs and Tian'anmen Square) time series, (b) the reconstructed $\Delta L S T$ time series and (c) the extracted trend of $\triangle L S T$. Each $\triangle L S T$ value is averaged from all pixels in the UGSs (Figure 1). The dashed lines indicate the breakpoints (1996 and 2000, respectively). The figures in the right panel are the mean annual $\Delta L S T$ composites from 2000 (d) and 2020 (e).

We also found that UGS daytime surface cooling significantly increased $(p<0.05, t$-test) to varying degrees in different seasons except for winter (Figure 7). The most noticeable cooling enhancement occurred on summer days (Figure 7a2-c2). Although vegetation provides strong cooling effects in summer, UGSs in the summer of 2000 did not show much lower $\triangle L S T$ values than those in spring and autumn, with a mean $\triangle L S T$ of approximately $-2{ }^{\circ} \mathrm{C}$. However, this was not the case in the summer of 2020, when the distribution of $\triangle L S T$ integrally shifted to the left (Figure 7c2), and the mean cooling effects increased to more than $4{ }^{\circ} \mathrm{C}$. This change was also illustrated by the fact that $88 \%$ of USG pixels represented a negative $\Delta L S T$ in 2000 , while the proportion had increased to $97 \%$ in 2020 (Figure 7c2). For spring and autumn, although the boundaries of $\Delta L S T$ remained almost unchanged during the two periods (Figure 7c1,c3), we observed evident left movements of the wave crests that resulted in mean cooling effect increases of $0.7^{\circ} \mathrm{C}$ for spring and $0.5^{\circ} \mathrm{C}$ for autumn. In winter, we failed to observe a significant cooling difference for UGSs. UGSs in both 2000 and 2020, on average, had a near-zero positive $\Delta L S T$ (Figure 7c4), implying their dim warming effects. 


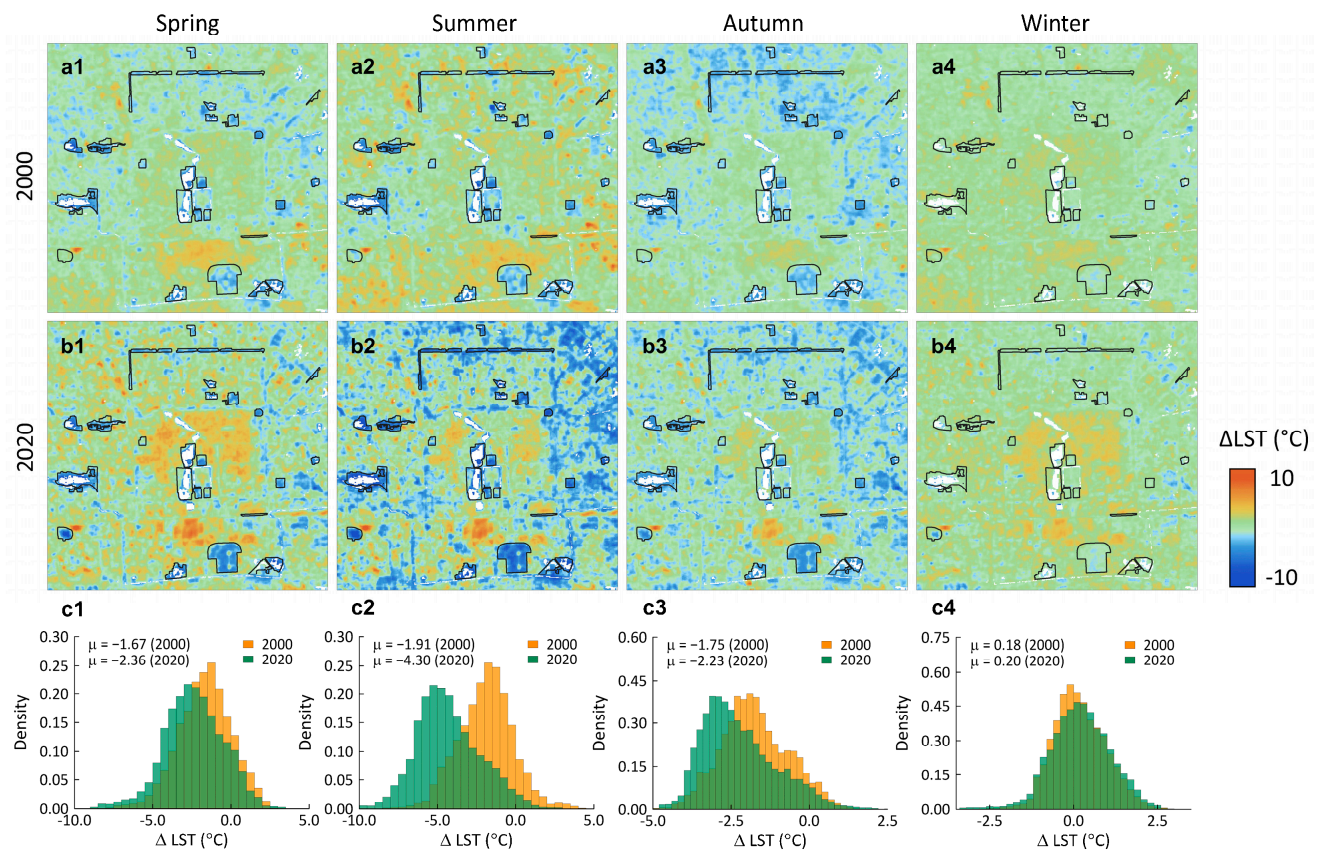

Figure 7. Dynamics of UGS surface cooling in different seasons. The figures in the first row are (a1) the $\Delta L S T$ (defined as the LST difference between UGSs and Tian'anmen Square) in the spring of 2000, (a2) summer, (a3) autumn and (a4) winter. The figures in the second row are (b1) the $\Delta L S T$ in the spring of 2020, (b2) summer, (b3) autumn and (b4) winter. The figures in the third row are (c1) the comparisons of the $\Delta L S T$ probability density distributions in 2000 and 2020 for spring, (c2) summer, (c3) autumn and (c4) winter with expectation ( $\mu$ ). The means of $\Delta L S T$ in spring, summer and autumn in 2000 were significantly larger $(p<0.05, t$-test) than those in 2020.

\subsection{Biophysical Mechanisms}

To explain the change in UGS surface-cooling effects, we established the dynamics of two main biophysical parameters (i.e., ET and albedo) that largely regulated vegetation heat exchange. ET characterizes the capability of vegetation to transfer sensible heat into latent heat, and vegetation with higher ET provides more cooling effects (transpiration cooling). In contrast, albedo represents how much incidental radiation can be absorbed by vegetation, and low albedo values imply that more energy will be absorbed to produce warming effects. Thus, a combined effect of transpiration cooling and albedo warming determines the final thermal responses to changes in vegetation conditions. As UGSs continued to turn greener, their ET and albedo values were positively and negatively responsive, respectively (Figure 8). For example, an increase in the NDVI before 1996 resulted in an increased mean annual ET $\left(0.50 \mathrm{~W} / \mathrm{m}^{2} /\right.$ year, Figure $\left.8 \mathrm{c} 2\right)$ and decreased mean annual albedo (-0.0007/year, Figure 8d2). After 2000, both Landsat and MODIS albedo showed negative responses (Figure 8d1) to the fast greenness increases in UGSs (Figure 8a1). These results indicate that the greening of UGS induced both the enhancement of transpiration cooling and albedo warming and vice versa in the period of greenness declination (1996-2000). 

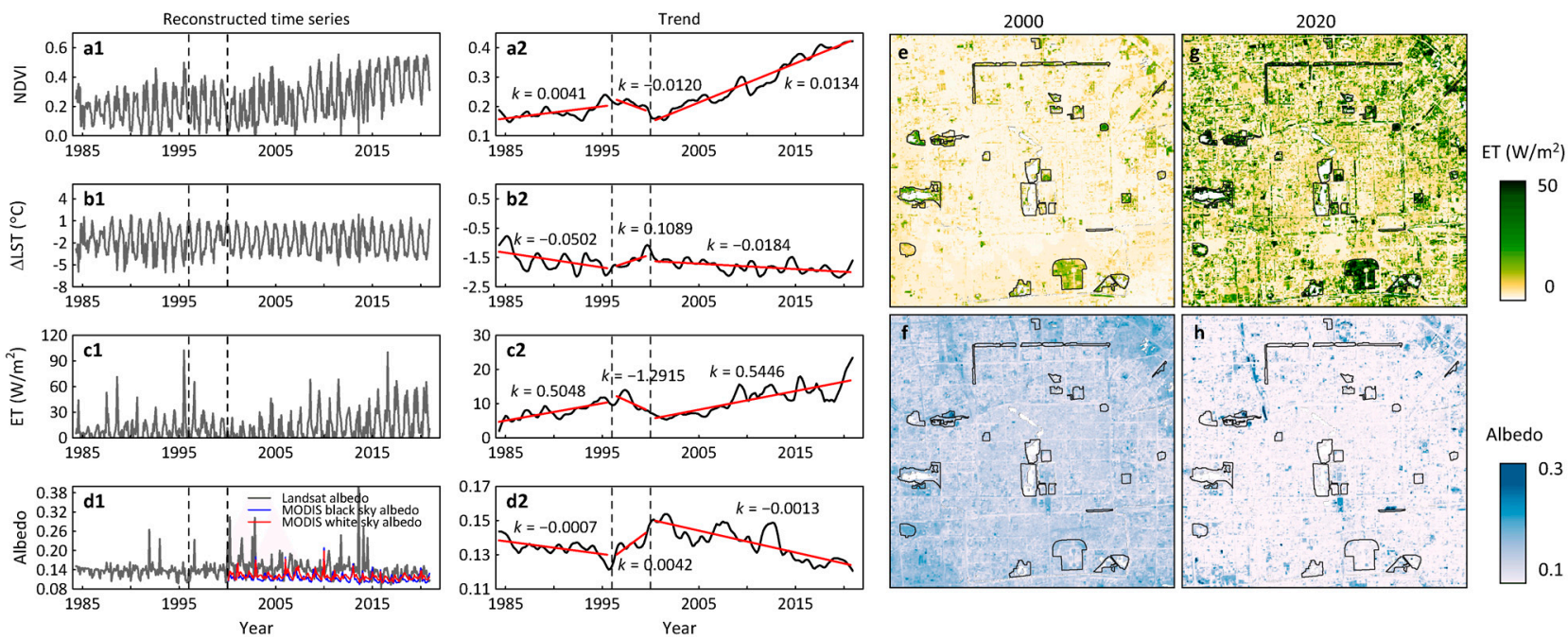

Figure 8. Dynamics of UGS evapotranspiration (ET) and albedo. The figures in the first panel are (a1) the reconstructed NDVI time series, (b1) the reconstructed $\triangle L S T$ time series, (c1) the reconstructed ET time series and (d1) the reconstructed albedo time series. The second panel shows (a2) the trend of the NDVI, (b2) the trend of the $\Delta L S T$, (c2) the trend of the ET and (d2) the trend of the albedo. The dashed lines indicate the breakpoints (1996 and 2000, respectively). The third and fourth panels show the mean annual evapotranspiration (ET) (e,g) and albedo (f,h) composites from 2000 and 2020.

Such competing biophysical changes resulted in segmented changes in UGS surface cooling (Figure 8b2). Due to the opposite thermal effects of ET and albedo, transpiration cooling dominated albedo warming in both the two greening periods (1984-1996 and 2000-2020) to provide discernable cooling enhancements. However, we found that a higher greening rate resulted in a lower cooling increase rate since the increase rate of UGS surface cooling after $2000\left(-0.018{ }^{\circ} \mathrm{C} /\right.$ year, Figure 8b2) was even less than half of that before $1996\left(-0.050^{\circ} \mathrm{C} /\right.$ year, Figure $\left.8 \mathrm{~b} 2\right)$. This could be related to the fact that albedo is more sensitive to UGS greening than ET with a comparison of the relative decrease rate of albedo $\left(\left(k_{2}-k_{1}\right) / k_{1}=85 \%\right.$, Figure $\left.8 \mathrm{~d} 2\right)$ and the relative increase rate of ET $\left(\left(k_{2}-k_{1}\right) / k_{1}=8 \%\right.$, Figure 8c2) in the two greening stages. Therefore, the cooling increase rate of UGS in the latter stage was largely offset by albedo-induced warming.

\section{Discussion}

\subsection{Greening of Urban Green Spaces}

The highlighted dynamics of UGS daytime cooling for the long run closely correlate with UGS vegetation conditions. Our results showed an overall increase in permanent UGS greenness during the past 40 years (1984-2020, Figure 5), implying that vegetation, at least in large UGSs, is healthier and more ecologically functional than it was before. This result may not be surprising because mainly due to $\mathrm{CO}_{2}$ fertilization, nitrogen deposition and climate changes, most of the planet has observed a phenomenon of 'greening' in recent decades $[55,56]$. High-intensity urbanization leads to higher radiation forces and temperatures, further enhancing vegetation growth and prolonging vegetation phenology to advance/delay the start/end of the growing season [57,58]. Furthermore, most Chinese UGSs are managed by municipal governments, and thus, they are more frequently influenced by human activities than UGSs in western cities [30]. After 2000, the Beijing Municipal Forestry and Parks Bureau implemented extensive park improvements, such as planting/replanting, transplanting, maintenance, protection from fire and diseases and the introduction of nonnative species. The activities play a critical role in vegetation (e.g., trees, shrubs, herbaceous plants) conditions and overall greenery coverage. For instance, more sophisticated management practices, e.g., better irrigation increases soil moisture to trigger vegetation greening [24], which is especially true for water-limited drylands. Other adverse effects, such as particulate matter accumulation, may decrease the photosynthetic 
rate to cause the poor performance of UGSs [59]. Indeed, a short-term greenness decline in 1996-2000 (Figure 5d) revealed a trough in UGSs, which was consistent with the contemporaneous field surveys conducted in the central part of Beijing that indicate trees in 2002 were mainly dominated by younger age classes and were in poor condition [60].

\subsection{The Necessity of Dynamic Monitoring of Urban Green Space Cooling Effects}

Because many of these possible driving forces vary with urban development and climate change, long-term monitoring becomes particularly important for urban vegetation eco-functional assessments. However, most existing conclusions related to UGS cooling effects have been drawn from contrast experiments conducted over a few years [11,61-63] or even on a single day $[64,65]$. Short-term observations might cause an over- or underestimation of long-term cooling potential to varying degrees, depending on how fast the urban area grows and how well UGSs are managed, as well as their interactions with changing environments. In this study, UGSs in the past 40 years suggested surface-cooling enhancements in all seasons ranging from less than $1{ }^{\circ} \mathrm{C}$ to more than $2{ }^{\circ} \mathrm{C}$. On warm summer days when UGSs are most needed to provide cooling, the large enhancements not only further reduce the surface temperature, but contribute to the formation of a convection cycle to provide canopy-layer cooling by subsiding the warmer urban air from above into UGSs and blowing their cooler air [66].

The cooling increase rate of UGS is not as fast as its greening rate because increasing transpiration cooling was largely offset by albedo-induced energy absorption, given the sharp decline of albedo since 2000 (Figure 8d2). This implies that more irrigation water might have been used to fulfill the increasing canopy transpiration demands, while the annually averaged surface-cooling benefits compared to 1984 were observed to be less than $1{ }^{\circ} \mathrm{C}$ (Figure $6 \mathrm{c}$ ). Although this study was conducted on permanent UGSs, the results have important implications for urban afforestation, since these changes in urban vegetation physiology could be harbingers of newly built green belts and urban parks and those areas that will be a large area of green spaces in the next decade. According to the Beijing urban master plan (2016-2035), multiple urban afforestation and greening programs will be conducted to increase per capita green space [12], and the city's overall forest cover rate should increase to no less than $45 \%$ in 2035. Therefore, urban planners and policymakers should consider the dynamics of the biophysical features of vegetation found in this study to balance the maintenance costs and the environmental gains in future UGS management.

\subsection{Limitations and Future Work}

The use of a series of Landsat-based datasets in this study is mainly due to its long temporal coverage (since 1984) and capacity to discern human-scale processes, such as the managed UGSs in Beijing. Because of its instantaneous imaging, which occurs at the satellite overpass time ( 10:53 a.m. local time in Beijing), our results represent the long-term dynamics of the biophysical characteristics of vegetation close to midday when illumination and water vapor reach their maximum and minimum, respectively. Thus, they inevitably sacrifice diurnal changes in $\triangle L S T$ and thus, UGS cooling effects. Additionally, due to the lack of nighttime high-resolution thermal infrared data, the temporal changes in $\triangle L S T$ are not evaluated at night when the urban heat island (UHI) intensity is generally strong. In addition, both LST and air temperature have been commonly used as key indicators measuring the UHI intensity or UGS cooling effects. However, despite high correlation, they are hardly comparable at the city scale because LST is the radiative skin temperature of the land surface that mainly depends on land use and land cover. In contrast, air temperature represents the thermal conditions of urban canopy layers, which are largely affected by geometry-induced advection [67]. Accordingly, future studies focusing on the dynamics of air temperature differences inside and outside growing UGSs are highly encouraged. 


\section{Conclusions}

Long-term dynamic monitoring plays a key role in the development and management of UGSs. Revealed by Landsat time series data on the past 40 years, we found segmented changes in UGS cooling effects that were mainly linked to the responses of canopy transpiration and albedo to vegetation conditions. During a rapid greening of UGSs in the recent two decades, transpiration cooling dominated albedo-induced warming to provide a discernable cooling enhancement, despite relatively more sensible changes in albedo. Such enhancement showed seasonal differences ranging from less than $1{ }^{\circ} \mathrm{C}$ to more than $2{ }^{\circ} \mathrm{C}$, and the most evident enhancements occurred on summer days $\left(\sim 2.4{ }^{\circ} \mathrm{C}\right)$. These findings extend the current understanding of UGS cooling effects and provide insights into how changes in vegetation physiology affect urban climate by altering the surface energy balance and the hydrologic cycle.

Author Contributions: Conceptualization, J.Z. and X.Z.; methodology, J.Z.; software, J.Z.; formal analysis, J.Z., X.Z., H.W. and D.W.; data curation, J.Z.; writing-original draft preparation, J.Z.; writing-review and editing, J.Z., X.Z., S.L., H.W., N.L., P.L. and D.W.; visualization, J.Z.; supervision, X.Z. and S.L.; project administration, X.Z. and S.L.; funding acquisition, X.Z. All authors have read and agreed to the published version of the manuscript.

Funding: This study was funded by the National Natural Science Foundation of China (42090012) and the National Key Research and Development Program of China (2016YFA0600103).

Institutional Review Board Statement: Not applicable.

Informed Consent Statement: Not applicable.

Data Availability Statement: Chinese urban park dataset is available at https:/ /www.beijingcitylab. com/data-released-1/data21-40/, accessed on 18 August 2021. Landsat surface reflectance images, MODIS images and NCEP/NCAR climate data are freely available on the Google Earth Engine (GEE) platform. Original time series data can be downloaded from Google Drive Cloud Storage (https: //drive.google.com/file/d/1X9-EcTeK3nPrNHvJWtMUhk-jRToSIg3F/view?usp=sharing, accessed on 18 August 2021).

Acknowledgments: We thank the three anonymous reviewers, academic editor and Qiang Liu at Beijing Normal University for their valuable comments on the manuscript.

Conflicts of Interest: The authors declare no conflict of interest.

\section{Appendix A}

Table A1. Metadata of the Landsat images used in this study.

\begin{tabular}{lrrr}
\hline Image Id & Date & Path & Row \\
\hline LT05_L1TP_123032_19840512_20170220_01_T1 & 12 May 1984 & 123 & 32 \\
LT05_L1TP_123032_19840629_20170220_01_T1 & 29 June 1984 & 123 & 32 \\
LT05_L1TP_123032_19840816_20170220_01_T1 & 16 August 1984 & 123 & 32 \\
LT05_L1TP_123032_19841003_20170220_01_T1 & 3 October 1984 & 123 & 32 \\
LT05_L1TP_123032_19841019_20170220_01_T1 & 19 October 1984 & 123 & 32 \\
LT05_L1TP_123032_19841120_20170220_01_T1 & 20 November 1984 & 123 & 32 \\
LT05_L1TP_123032_19841222_20170219_01_T1 & 22 December 1984 & 123 & 32 \\
LT05_L1TP_123032_19850312_20170219_01_T1 & 12 March 1985 & 123 & 32 \\
LT05_L1TP_123032_19851022_20170218_01_T1 & 22 October 1985 & 123 & 32 \\
LT05_L1TP_123032_19860110_20170218_01_T1 & 10 January 1986 & 123 & 32 \\
LT05_L1TP_123032_19860227_20170218_01_T1 & 27 February 1986 & 123 & 32 \\
LT05_L1TP_123032_19860315_20170218_01_T1 & 15 March 1986 & 123 & 32 \\
LT05_L1TP_123032_19860331_20170218_01_T1 & 31 March 1986 & 123 & 32 \\
LT05_L1TP_123032_19860416_20170221_01_T1 & 16 April 1986 & 123 & 32 \\
LT05_L1TP_123032_19860603_20170221_01_T1 & 3 June 1986 & 123 & 32 \\
LT05_L1TP_123032_19861025_20170221_01_T1 & 25 October 1986 & 123 & 32 \\
LT05_L1TP_123032_19861110_20170221_01_T1 & 10 November 1986 & 123 & 32 \\
\hline
\end{tabular}


Table A1. Cont.

\begin{tabular}{|c|c|c|c|}
\hline Image Id & Date & Path & Row \\
\hline LT05_L1TP_123032_19861126_20170221_01_T1 & 26 November 1986 & 123 & 32 \\
\hline LT05_L1TP_123032_19870403_20170213_01_T1 & 3 April 1987 & 123 & 32 \\
\hline LT05_L1TP_123032_19870708_20170212_01_T1 & 8 July 1987 & 123 & 32 \\
\hline LT05_L1TP_123032_19870910_20170211_01_T1 & 10 September 1987 & 123 & 32 \\
\hline LT05_L1TP_123032_19870926_20170418_01_T1 & 26 September 1987 & 123 & 32 \\
\hline LT05_L1TP_123032_19871215_20170210_01_T1 & 15 December 1987 & 123 & 32 \\
\hline LT05_L1TP_123032_19871231_20170418_01_T1 & 31 December 1987 & 123 & 32 \\
\hline LT05_L1TP_123032_19880116_20170221_01_T1 & 16 January 1988 & 123 & 32 \\
\hline LT05_L1TP_123032_19880201_20170209_01_T1 & 1 February 1988 & 123 & 32 \\
\hline LT05_L1TP_123032_19880217_20170209_01_T1 & 17 February 1988 & 123 & 32 \\
\hline LT05_L1TP_123032_19880304_20170209_01_T1 & 4 March 1988 & 123 & 32 \\
\hline LT05_L1TP_123032_19880405_20170209_01_T1 & 5 April 1988 & 123 & 32 \\
\hline LT05_L1TP_123032_19880421_20170221_01_T1 & 21 April 1988 & 123 & 32 \\
\hline LT05_L1TP_123032_19880507_20170221_01_T1 & 7 May 1988 & 123 & 32 \\
\hline LT05_L1TP_123032_19880811_20170207_01_T1 & 11 August 1988 & 123 & 32 \\
\hline LT05_L1TP_123032_19880928_20170205_01_T1 & 28 September 1988 & 123 & 32 \\
\hline LT05_L1TP_123032_19881014_20170206_01_T1 & 14 October 1988 & 123 & 32 \\
\hline LT05_L1TP_123032_19881030_20170221_01_T1 & 30 October 1988 & 123 & 32 \\
\hline LT05_L1TP_123032_19881201_20170205_01_T1 & 1 December 1988 & 123 & 32 \\
\hline LT05_L1TP_123032_19881217_20170205_01_T1 & 17 December 1988 & 123 & 32 \\
\hline LT05_L1TP_123032_19890307_20170204_01_T1 & 7 March 1989 & 123 & 32 \\
\hline LT05_L1TP_123032_19890408_20170204_01_T1 & 8 April 1989 & 123 & 32 \\
\hline LT05_L1TP_123032_19890526_20170203_01_T1 & 26 May 1989 & 123 & 32 \\
\hline LT05_L1TP_123032_19890627_20170202_01_T1 & 27 June 1989 & 123 & 32 \\
\hline LT05_L1TP_123032_19890814_20170202_01_T1 & 14 August 1989 & 123 & 32 \\
\hline LT05_L1TP_123032_19890830_20170214_01_T1 & 30 August 1989 & 123 & 32 \\
\hline LT05_L1TP_123032_19891001_20170214_01_T1 & 1 October 1989 & 123 & 32 \\
\hline LT05_L1TP_123032_19891017_20170201_01_T1 & 17 October 1989 & 123 & 32 \\
\hline LT05_L1TP_123032_19891102_20170201_01_T1 & 2 November 1989 & 123 & 32 \\
\hline LT05_L1TP_123032_19891118_20170201_01_T1 & 18 November 1989 & 123 & 32 \\
\hline LT05_L1TP_123032_19891204_20170201_01_T1 & 4 December 1989 & 123 & 32 \\
\hline LT05_L1TP_123032_19891220_20170201_01_T1 & 20 December 1989 & 123 & 32 \\
\hline LT05_L1TP_123032_19900105_20170201_01_T1 & 5 January 1990 & 123 & 32 \\
\hline LT05_L1TP_123032_19900121_20170214_01_T1 & 21 January 1990 & 123 & 32 \\
\hline LT05_L1TP_123032_19900206_20170131_01_T1 & 6 February 1990 & 123 & 32 \\
\hline LT05_L1TP_123032_19900326_20170131_01_T1 & 26 March 1990 & 123 & 32 \\
\hline LT05_L1TP_123032_19900427_20170131_01_T1 & 27 April 1990 & 123 & 32 \\
\hline LT05_L1TP_123032_19900513_20170214_01_T1 & 13 May 1990 & 123 & 32 \\
\hline LT05_L1TP_123032_19900529_20170131_01_T1 & 29 May 1990 & 123 & 32 \\
\hline LT05_L1TP_123032_19900614_20170129_01_T1 & 14 June 1990 & 123 & 32 \\
\hline LT05_L1TP_123032_19900716_20170129_01_T1 & 16 July 1990 & 123 & 32 \\
\hline LT05_L1TP_123032_19900902_20170129_01_T1 & 2 September 1990 & 123 & 32 \\
\hline LT05_L1TP_123032_19900918_20170129_01_T1 & 18 September 1990 & 123 & 32 \\
\hline LT05_L1TP_123032_19901020_20170129_01_T1 & 20 October 1990 & 123 & 32 \\
\hline LT05_L1TP_123032_19901121_20180620_01_T1 & 21 November 1990 & 123 & 32 \\
\hline LT05_L1TP_123032_19901207_20170128_01_T1 & 7 December 1990 & 123 & 32 \\
\hline LT05_L1TP_123032_19901223_20170214_01_T1 & 23 December 1990 & 123 & 32 \\
\hline LT05_L1TP_123032_19910108_20170128_01_T1 & January 8, 1991 & 123 & 32 \\
\hline LT05_L1TP_123032_19910124_20170128_01_T1 & 24 January 1991 & 123 & 32 \\
\hline LT05_L1TP_123032_19910225_20170127_01_T1 & 25 February 1991 & 123 & 32 \\
\hline LT05_L1TP_123032_19910313_20170127_01_T1 & 13 March 1991 & 123 & 32 \\
\hline LT05_L1TP_123032_19910329_20170127_01_T1 & 29 March 1991 & 123 & 32 \\
\hline LT05_L1TP_123032_19910516_20170127_01_T1 & 16 May 1991 & 123 & 32 \\
\hline LT05_L1TP_123032_19910617_20170126_01_T1 & 17 June 1991 & 123 & 32 \\
\hline LT05_L1TP_123032_19910804_20170125_01_T1 & 4 August 1991 & 123 & 32 \\
\hline LT05_L1TP_123032_19910905_20170125_01_T1 & 5 September 1991 & 123 & 32 \\
\hline LT05_L1TP_123032_19910921_20170125_01_T1 & 21 September 1991 & 123 & 32 \\
\hline
\end{tabular}


Table A1. Cont.

\begin{tabular}{|c|c|c|c|}
\hline Image Id & Date & Path & Row \\
\hline LT05_L1TP_123032_19911007_20180619_01_T1 & 7 October 1991 & 123 & 32 \\
\hline LT05_L1TP_123032_19911023_20170125_01_T1 & 23 October 1991 & 123 & 32 \\
\hline LT05_L1TP_123032_19911108_20170125_01_T1 & 8 November 1991 & 123 & 32 \\
\hline LT05_L1TP_123032_19911124_20170125_01_T1 & 24 November 1991 & 123 & 32 \\
\hline LT05_L1TP_123032_19911210_20170124_01_T1 & 10 December 1991 & 123 & 32 \\
\hline LT05_L1TP_123032_19920127_20170123_01_T1 & 27 January 1992 & 123 & 32 \\
\hline LT05_L1TP_123032_19920212_20170123_01_T1 & 12 February 1992 & 123 & 32 \\
\hline LT05_L1TP_123032_19920228_20170124_01_T1 & 28 February 1992 & 123 & 32 \\
\hline LT05_L1TP_123032_19920416_20170123_01_T1 & 16 April 1992 & 123 & 32 \\
\hline LT05_L1TP_123032_19920518_20170122_01_T1 & 18 May 1992 & 123 & 32 \\
\hline LT05_L1TP_123032_19920603_20170124_01_T1 & 3 June 1992 & 123 & 32 \\
\hline LT05_L1TP_123032_19920619_20170123_01_T1 & 19 June 1992 & 123 & 32 \\
\hline LT05_L1TP_123032_19920822_20170214_01_T1 & 22 August 1992 & 123 & 32 \\
\hline LT05_L1TP_123032_19920907_20170122_01_T1 & 7 September 1992 & 123 & 32 \\
\hline LT05_L1TP_123032_19921009_20170214_01_T1 & 9 October 1992 & 123 & 32 \\
\hline LT05_L1TP_123032_19921025_20170214_01_T1 & 25 October 1992 & 123 & 32 \\
\hline LT05_L1TP_123032_19921110_20170214_01_T1 & 10 November 1992 & 123 & 32 \\
\hline LT05_L1TP_123032_19921126_20170121_01_T1 & 26 November 1992 & 123 & 32 \\
\hline LT05_L1TP_123032_19921212_20170214_01_T1 & 12 December 1992 & 123 & 32 \\
\hline LT05_L1TP_123032_19921228_20170121_01_T1 & 28 December 1992 & 123 & 32 \\
\hline LT05_L1TP_123032_19930113_20170120_01_T1 & 13 January 1993 & 123 & 32 \\
\hline LT05_L1TP_123032_19930129_20170120_01_T1 & 29 January 1993 & 123 & 32 \\
\hline LT05_L1TP_123032_19930214_20170120_01_T1 & 14 February 1993 & 123 & 32 \\
\hline LT05_L1TP_123032_19930302_20170120_01_T1 & 2 March 1993 & 123 & 32 \\
\hline LT05_L1TP_123032_19930318_20170119_01_T1 & 18 March 1993 & 123 & 32 \\
\hline LT05_L1TP_123032_19930606_20170118_01_T1 & 6 June 1993 & 123 & 32 \\
\hline LT05_L1TP_123032_19930622_20170118_01_T1 & 22 June 1993 & 123 & 32 \\
\hline LT05_L1TP_123032_19930809_20180620_01_T1 & 9 August 1993 & 123 & 32 \\
\hline LT05_L1TP_123032_19930825_20170117_01_T1 & 25 August 1993 & 123 & 32 \\
\hline LT05_L1TP_123032_19931215_20170116_01_T1 & 15 December 1993 & 123 & 32 \\
\hline LT05_L1TP_123032_19931231_20170117_01_T1 & 31 December 1993 & 123 & 32 \\
\hline LT05_L1TP_123032_19940321_20170114_01_T1 & 21 March 1994 & 123 & 32 \\
\hline LT05_L1TP_123032_19940406_20180619_01_T1 & 6 April 1994 & 123 & 32 \\
\hline LT05_L1TP_123032_19940508_20170114_01_T1 & 8 May 1994 & 123 & 32 \\
\hline LT05_L1TP_123032_19940609_20170113_01_T1 & 9 June 1994 & 123 & 32 \\
\hline LT05_L1TP_123032_19940913_20170112_01_T1 & 13 September 1994 & 123 & 32 \\
\hline LT05_L1TP_123032_19940929_20170112_01_T1 & 29 September 1994 & 123 & 32 \\
\hline LT05_L1TP_123032_19941031_20170112_01_T1 & 31 October 1994 & 123 & 32 \\
\hline LT05_L1TP_123032_19941202_20170110_01_T1 & 2 December 1994 & 123 & 32 \\
\hline LT05_L1TP_123032_19941218_20170110_01_T1 & 18 December 1994 & 123 & 32 \\
\hline LT05_L1TP_123032_19950409_20170108_01_T1 & 9 April 1995 & 123 & 32 \\
\hline LT05_L1TP_123032_19950425_20170108_01_T1 & 25 April 1995 & 123 & 32 \\
\hline LT05_L1TP_123032_19950612_20170107_01_T1 & 12 June 1995 & 123 & 32 \\
\hline LT05_L1TP_123032_19950628_20170107_01_T1 & 28 June 1995 & 123 & 32 \\
\hline LT05_L1TP_123032_19950730_20170107_01_T1 & 30 July 1995 & 123 & 32 \\
\hline LT05_L1TP_123032_19950815_20170107_01_T1 & 15 August 1995 & 123 & 32 \\
\hline LT05_L1TP_123032_19950916_20170107_01_T1 & 16 September 1995 & 123 & 32 \\
\hline LT05_L1TP_123032_19951018_20170107_01_T1 & 18 October 1995 & 123 & 32 \\
\hline LT05_L1TP_123032_19951119_20170107_01_T1 & 19 November 1995 & 123 & 32 \\
\hline LT05_L1TP_123032_19951205_20170106_01_T1 & 5 December 1995 & 123 & 32 \\
\hline LT05_L1TP_123032_19951221_20170106_01_T1 & 21 December 1995 & 123 & 32 \\
\hline LT05_L1TP_123032_19960207_20170106_01_T1 & 7 February 1996 & 123 & 32 \\
\hline LT05_L1TP_123032_19960223_20170106_01_T1 & 23 February 1996 & 123 & 32 \\
\hline LT05_L1TP_123032_19960310_20170105_01_T1 & 10 March 1996 & 123 & 32 \\
\hline LT05_L1TP_123032_19960326_20170105_01_T1 & 26 March 1996 & 123 & 32 \\
\hline LT05_L1TP_123032_19960411_20170105_01_T1 & 11 April 1996 & 123 & 32 \\
\hline LT05_L1TP_123032_19960427_20170105_01_T1 & 27 April 1996 & 123 & 32 \\
\hline
\end{tabular}


Table A1. Cont.

\begin{tabular}{|c|c|c|c|}
\hline Image Id & Date & Path & Row \\
\hline LT05_L1TP_123032_19960513_20170104_01_T1 & 13 May 1996 & 123 & 32 \\
\hline LT05_L1TP_123032_19960529_20170104_01_T1 & 29 May 1996 & 123 & 32 \\
\hline LT05_L1TP_123032_19960614_20170104_01_T1 & 14 June 1996 & 123 & 32 \\
\hline LT05_L1TP_123032_19960630_20170104_01_T1 & 30 June 1996 & 123 & 32 \\
\hline LT05_L1TP_123032_19960817_20180620_01_T1 & 17 August 1996 & 123 & 32 \\
\hline LT05_L1TP_123032_19970209_20180620_01_T1 & 9 February 1997 & 123 & 32 \\
\hline LT05_L1TP_123032_19970430_20161231_01_T1 & 30 April 1997 & 123 & 32 \\
\hline LT05_L1TP_123032_19970516_20161231_01_T1 & 16 May 1997 & 123 & 32 \\
\hline LT05_L1TP_123032_19970804_20161230_01_T1 & 4 August 1997 & 123 & 32 \\
\hline LT05_L1TP_123032_19970921_20161229_01_T1 & 21 September 1997 & 123 & 32 \\
\hline LT05_L1TP_123032_19971007_20180620_01_T1 & 7 October 1997 & 123 & 32 \\
\hline LT05_L1TP_123032_19971023_20161229_01_T1 & 23 October 1997 & 123 & 32 \\
\hline LT05_L1TP_123032_19971108_20161229_01_T1 & 8 November 1997 & 123 & 32 \\
\hline LT05_L1TP_123032_19971210_20161228_01_T1 & 10 December 1997 & 123 & 32 \\
\hline LT05_L1TP_123032_19971226_20161228_01_T1 & 26 December 1997 & 123 & 32 \\
\hline LT05_L1TP_123032_19980417_20161225_01_T1 & 17 April 1998 & 123 & 32 \\
\hline LT05_L1TP_123032_19980823_20161223_01_T1 & 23 August 1998 & 123 & 32 \\
\hline LT05_L1TP_123032_19980924_20161221_01_T1 & 24 September 1998 & 123 & 32 \\
\hline LT05_L1TP_123032_19981111_20161220_01_T1 & 11 November 1998 & 123 & 32 \\
\hline LT05_L1TP_123032_19981127_20161222_01_T1 & 27 November 1998 & 123 & 32 \\
\hline LT05_L1TP_123032_19981213_20161220_01_T1 & 13 December 1998 & 123 & 32 \\
\hline LT05_L1TP_123032_19981229_20161222_01_T1 & 29 December 1998 & 123 & 32 \\
\hline LT05_L1TP_123032_19990114_20161219_01_T1 & 14 January 1999 & 123 & 32 \\
\hline LT05_L1TP_123032_19990130_20161219_01_T1 & 30 January 1999 & 123 & 32 \\
\hline LT05_L1TP_123032_19990303_20161220_01_T1 & 3 March 1999 & 123 & 32 \\
\hline LT05_L1TP_123032_19990506_20161218_01_T1 & 6 May 1999 & 123 & 32 \\
\hline LT05_L1TP_123032_19990607_20161217_01_T1 & 7 June 1999 & 123 & 32 \\
\hline LT05_L1TP_123032_19990623_20161217_01_T1 & 23 June 1999 & 123 & 32 \\
\hline LT05_L1TP_123032_19990709_20161217_01_T1 & 9 July 1999 & 123 & 32 \\
\hline LT05_L1TP_123032_19990725_20161219_01_T1 & 25 July 1999 & 123 & 32 \\
\hline LT05_L1TP_123032_19990810_20161216_01_T1 & 10 August 1999 & 123 & 32 \\
\hline LT05_L1TP_123032_19990826_20161216_01_T1 & 26 August 1999 & 123 & 32 \\
\hline LT05_L1TP_123032_19991013_20161216_01_T1 & 13 October 1999 & 123 & 32 \\
\hline LT05_L1TP_123032_19991029_20161216_01_T1 & 29 October 1999 & 123 & 32 \\
\hline LT05_L1TP_123032_19991114_20180620_01_T1 & 14 November 1999 & 123 & 32 \\
\hline LT05_L1TP_123032_19991130_20161216_01_T1 & 30 November 1999 & 123 & 32 \\
\hline LT05_L1TP_123032_20000117_20161215_01_T1 & 17 January 2000 & 123 & 32 \\
\hline LT05_L1TP_123032_20000202_20161216_01_T1 & 2 February 2000 & 123 & 32 \\
\hline LT05_L1TP_123032_20000305_20161215_01_T1 & 5 March 2000 & 123 & 32 \\
\hline LT05_L1TP_123032_20000321_20161214_01_T1 & 21 March 2000 & 123 & 32 \\
\hline LT05_L1TP_123032_20000406_20161214_01_T1 & 6 April 2000 & 123 & 32 \\
\hline LT05_L1TP_123032_20000524_20161214_01_T1 & 24 May 2000 & 123 & 32 \\
\hline LT05_L1TP_123032_20000828_20161213_01_T1 & 28 August 2000 & 123 & 32 \\
\hline LT05_L1TP_123032_20000913_20161214_01_T1 & 13 September 2000 & 123 & 32 \\
\hline LT05_L1TP_123032_20000929_20161213_01_T1 & 29 September 2000 & 123 & 32 \\
\hline LT05_L1TP_123032_20001031_20161213_01_T1 & 31 October 2000 & 123 & 32 \\
\hline LT05_L1TP_123032_20001218_20161212_01_T1 & 18 December 2000 & 123 & 32 \\
\hline LT05_L1TP_123032_20010103_20161212_01_T1 & 3 January 2001 & 123 & 32 \\
\hline LT05_L1TP_123032_20010119_20161212_01_T1 & 19 January 2001 & 123 & 32 \\
\hline LT05_L1TP_123032_20010324_20161212_01_T1 & 24 March 2001 & 123 & 32 \\
\hline LT05_L1TP_123032_20010628_20161211_01_T1 & 28 June 2001 & 123 & 32 \\
\hline LT05_L1TP_123032_20010730_20161210_01_T1 & 30 July 2001 & 123 & 32 \\
\hline LT05_L1TP_123032_20010831_20161210_01_T1 & 31 August 2001 & 123 & 32 \\
\hline LT05_L1TP_123032_20011018_20161209_01_T1 & 18 October 2001 & 123 & 32 \\
\hline LT05_L1TP_123032_20011103_20161209_01_T1 & 3 November 2001 & 123 & 32 \\
\hline LT05_L1TP_123032_20011119_20161210_01_T1 & 19 November 2001 & 123 & 32 \\
\hline LT05_L1TP_123032_20011221_20161210_01_T1 & 21 December 2001 & 123 & 32 \\
\hline
\end{tabular}


Table A1. Cont.

\begin{tabular}{|c|c|c|c|}
\hline Image Id & Date & Path & Row \\
\hline LT05_L1TP_123032_20020122_20161209_01_T1 & 22 January 2002 & 123 & 32 \\
\hline LT05_L1TP_123032_20020207_20161209_01_T1 & 7 February 2002 & 123 & 32 \\
\hline LT05_L1TP_123032_20020223_20161208_01_T1 & 23 February 2002 & 123 & 32 \\
\hline LT05_L1TP_123032_20020311_20161209_01_T1 & 11 March 2002 & 123 & 32 \\
\hline LT05_L1TP_123032_20020717_20161207_01_T1 & 17 July 2002 & 123 & 32 \\
\hline LT05_L1TP_123032_20020802_20161207_01_T1 & 2 August 2002 & 123 & 32 \\
\hline LT05_L1TP_123032_20020818_20161207_01_T1 & 18 August 2002 & 123 & 32 \\
\hline LT05_L1TP_123032_20021005_20161206_01_T1 & 5 October 2002 & 123 & 32 \\
\hline LT05_L1TP_123032_20021106_20161206_01_T1 & 6 November 2002 & 123 & 32 \\
\hline LT05_L1TP_123032_20021208_20161207_01_T1 & 8 December 2002 & 123 & 32 \\
\hline LT05_L1TP_123032_20030109_20161206_01_T1 & 9 January 2003 & 123 & 32 \\
\hline LT05_L1TP_123032_20030210_20161206_01_T1 & 10 February 2003 & 123 & 32 \\
\hline LT05_L1TP_123032_20030226_20161206_01_T1 & 26 February 2003 & 123 & 32 \\
\hline LT05_L1TP_123032_20030517_20161206_01_T1 & 17 May 2003 & 123 & 32 \\
\hline LT05_L1TP_123032_20030922_20161204_01_T1 & 22 September 2003 & 123 & 32 \\
\hline LT05_L1TP_123032_20031024_20161204_01_T1 & 24 October 2003 & 123 & 32 \\
\hline LT05_L1TP_123032_20031211_20161204_01_T1 & 11 December 2003 & 123 & 32 \\
\hline LT05_L1TP_123032_20031227_20161203_01_T1 & 27 December 2003 & 123 & 32 \\
\hline LT05_L1TP_123032_20040112_20161202_01_T1 & 12 January 2004 & 123 & 32 \\
\hline LT05_L1TP_123032_20040128_20161203_01_T1 & 28 January 2004 & 123 & 32 \\
\hline LT05_L1TP_123032_20040401_20161203_01_T1 & 1 April 2004 & 123 & 32 \\
\hline LT05_L1TP_123032_20040519_20161201_01_T1 & 19 May 2004 & 123 & 32 \\
\hline LT05_L1TP_123032_20040706_20161130_01_T1 & 6 July 2004 & 123 & 32 \\
\hline LT05_L1TP_123032_20040823_20161129_01_T1 & 23 August 2004 & 123 & 32 \\
\hline LT05_L1TP_123032_20040908_20161129_01_T1 & 8 September 2004 & 123 & 32 \\
\hline LT05_L1TP_123032_20041026_20161128_01_T1 & 26 October 2004 & 123 & 32 \\
\hline LT05_L1TP_123032_20041127_20161128_01_T1 & 27 November 2004 & 123 & 32 \\
\hline LT05_L1TP_123032_20041213_20161127_01_T1 & 13 December 2004 & 123 & 32 \\
\hline LT05_L1TP_123032_20041229_20161129_01_T1 & 29 December 2004 & 123 & 32 \\
\hline LT05_L1TP_123032_20050319_20161128_01_T1 & 19 March 2005 & 123 & 32 \\
\hline LT05_L1TP_123032_20050522_20161127_01_T1 & 22 May 2005 & 123 & 32 \\
\hline LT05_L1TP_123032_20050607_20161125_01_T1 & 7 June 2005 & 123 & 32 \\
\hline LT05_L1TP_123032_20050709_20161125_01_T1 & 9 July 2005 & 123 & 32 \\
\hline LT05_L1TP_123032_20050725_20161125_01_T1 & 25 July 2005 & 123 & 32 \\
\hline LT05_L1TP_123032_20050911_20161124_01_T1 & 11 September 2005 & 123 & 32 \\
\hline LT05_L1TP_123032_20050927_20161124_01_T1 & 27 September 2005 & 123 & 32 \\
\hline LT05_L1TP_123032_20051029_20161123_01_T1 & 29 October 2005 & 123 & 32 \\
\hline LT05_L1TP_123032_20051114_20161124_01_T1 & 14 November 2005 & 123 & 32 \\
\hline LT05_L1TP_123032_20060202_20161123_01_T1 & 2 February 2006 & 123 & 32 \\
\hline LT05_L1TP_123032_20060218_20161123_01_T1 & 18 February 2006 & 123 & 32 \\
\hline LT05_L1TP_123032_20060306_20161123_01_T1 & 6 March 2006 & 123 & 32 \\
\hline LT05_L1TP_123032_20060407_20161123_01_T1 & 7 April 2006 & 123 & 32 \\
\hline LT05_L1TP_123032_20060610_20161121_01_T1 & 10 June 2006 & 123 & 32 \\
\hline LT05_L1TP_123032_20060626_20161121_01_T1 & 26 June 2006 & 123 & 32 \\
\hline LT05_L1TP_123032_20060712_20161120_01_T1 & 12 July 2006 & 123 & 32 \\
\hline LT05_L1TP_123032_20060930_20161119_01_T1 & 30 September 2006 & 123 & 32 \\
\hline LT05_L1TP_123032_20061101_20161118_01_T1 & 1 November 2006 & 123 & 32 \\
\hline LT05_L1TP_123032_20061203_20161118_01_T1 & 3 December 2006 & 123 & 32 \\
\hline LT05_L1TP_123032_20061219_20161118_01_T1 & 19 December 2006 & 123 & 32 \\
\hline LT05_L1TP_123032_20070104_20161117_01_T1 & 4 January 2007 & 123 & 32 \\
\hline LT05_L1TP_123032_20070120_20161117_01_T1 & 20 January 2007 & 123 & 32 \\
\hline LT05_L1TP_123032_20070309_20161116_01_T1 & 9 March 2007 & 123 & 32 \\
\hline LT05_L1TP_123032_20070410_20161115_01_T1 & 10 April 2007 & 123 & 32 \\
\hline LT05_L1TP_123032_20070426_20161115_01_T1 & 26 April 2007 & 123 & 32 \\
\hline LT05_L1TP_123032_20070512_20161115_01_T1 & 12 May 2007 & 123 & 32 \\
\hline LT05_L1TP_123032_20070528_20161114_01_T1 & 28 May 2007 & 123 & 32 \\
\hline LT05_L1TP_123032_20070901_20161113_01_T1 & 1 September 2007 & 123 & 32 \\
\hline
\end{tabular}


Table A1. Cont.

\begin{tabular}{|c|c|c|c|}
\hline Image Id & Date & Path & Row \\
\hline LT05_L1TP_123032_20071003_20161110_01_T1 & 3 October 2007 & 123 & 32 \\
\hline LT05_L1TP_123032_20080208_20161101_01_T1 & 8 February 2008 & 123 & 32 \\
\hline LT05_L1TP_123032_20080327_20161101_01_T1 & 27 March 2008 & 123 & 32 \\
\hline LT05_L1TP_123032_20080428_20161101_01_T1 & 28 April 2008 & 123 & 32 \\
\hline LT05_L1TP_123032_20080514_20161031_01_T1 & 14 May 2008 & 123 & 32 \\
\hline LT05_L1TP_123032_20080530_20161031_01_T1 & 30 May 2008 & 123 & 32 \\
\hline LT05_L1TP_123032_20080802_20161030_01_T1 & 2 August 2008 & 123 & 32 \\
\hline LT05_L1TP_123032_20080818_20170613_01_T1 & 18 August 2008 & 123 & 32 \\
\hline LT05_L1TP_123032_20090125_20161029_01_T1 & 25 January 2009 & 123 & 32 \\
\hline LT05_L1TP_123032_20090210_20161028_01_T1 & 10 February 2009 & 123 & 32 \\
\hline LT05_L1TP_123032_20090226_20161027_01_T1 & 26 February 2009 & 123 & 32 \\
\hline LT05_L1TP_123032_20090314_20161027_01_T1 & 14 March 2009 & 123 & 32 \\
\hline LT05_L1TP_123032_20090330_20161027_01_T1 & 30 March 2009 & 123 & 32 \\
\hline LT05_L1TP_123032_20090415_20161027_01_T1 & 15 April 2009 & 123 & 32 \\
\hline LT05_L1TP_123032_20090517_20161026_01_T1 & 17 May 2009 & 123 & 32 \\
\hline LT05_L1TP_123032_20090602_20161025_01_T1 & 2 June 2009 & 123 & 32 \\
\hline LT05_L1TP_123032_20090720_20161027_01_T1 & 20 July 2009 & 123 & 32 \\
\hline LT05_L1TP_123032_20090922_20161020_01_T1 & 22 September 2009 & 123 & 32 \\
\hline LT05_L1TP_123032_20091024_20161024_01_T1 & 24 October 2009 & 123 & 32 \\
\hline LT05_L1TP_123032_20100128_20161017_01_T1 & 28 January 2010 & 123 & 32 \\
\hline LT05_L1TP_123032_20100213_20161016_01_T1 & 13 February 2010 & 123 & 32 \\
\hline LT05_L1TP_123032_20100317_20161016_01_T1 & 17 March 2010 & 123 & 32 \\
\hline LT05_L1TP_123032_20100402_20161016_01_T1 & 2 April 2010 & 123 & 32 \\
\hline LT05_L1TP_123032_20100418_20161015_01_T1 & 18 April 2010 & 123 & 32 \\
\hline LT05_L1TP_123032_20100504_20161015_01_T1 & 4 May 2010 & 123 & 32 \\
\hline LT05_L1TP_123032_20100520_20161015_01_T1 & 20 May 2010 & 123 & 32 \\
\hline LT05_L1TP_123032_20100605_20161015_01_T1 & 5 June 2010 & 123 & 32 \\
\hline LT05_L1TP_123032_20100723_20161014_01_T1 & 23 July 2010 & 123 & 32 \\
\hline LT05_L1TP_123032_20100808_20161014_01_T1 & 8 August 2010 & 123 & 32 \\
\hline LT05_L1TP_123032_20100824_20161014_01_T1 & 24 August 2010 & 123 & 32 \\
\hline LT05_L1TP_123032_20101011_20161012_01_T1 & 11 October 2010 & 123 & 32 \\
\hline LT05_L1TP_123032_20101128_20161012_01_T1 & 28 November 2010 & 123 & 32 \\
\hline LT05_L1TP_123032_20101214_20161011_01_T1 & 14 December 2010 & 123 & 32 \\
\hline LT05_L1TP_123032_20110115_20161010_01_T1 & 15 January 2011 & 123 & 32 \\
\hline LT05_L1TP_123032_20110131_20161010_01_T1 & 31 January 2011 & 123 & 32 \\
\hline LT05_L1TP_123032_20110304_20161210_01_T1 & 4 March 2011 & 123 & 32 \\
\hline LT05_L1TP_123032_20110405_20161208_01_T1 & 5 April 2011 & 123 & 32 \\
\hline LT05_L1TP_123032_20110507_20161009_01_T1 & 7 May 2011 & 123 & 32 \\
\hline LT05_L1TP_123032_20110523_20161010_01_T1 & 23 May 2011 & 123 & 32 \\
\hline LT05_L1TP_123032_20110608_20161009_01_T1 & 8 June 2011 & 123 & 32 \\
\hline LT05_L1TP_123032_20110726_20161007_01_T1 & 26 July 2011 & 123 & 32 \\
\hline LT05_L1TP_123032_20111030_20161005_01_T1 & 30 October 2011 & 123 & 32 \\
\hline LC08_L1TP_124032_20130410_20200913_02_T1 & 10 April 2013 & 124 & 32 \\
\hline LC08_L1TP_123032_20130512_20200912_02_T1 & 12 May 2013 & 123 & 32 \\
\hline LC08_L1TP_123032_20130613_20200912_02_T1 & 13 June 2013 & 123 & 32 \\
\hline LC08_L1TP_123032_20130731_20200912_02_T1 & 31 July 2013 & 123 & 32 \\
\hline LC08_L1TP_123032_20130816_20200912_02_T1 & 16 August 2013 & 123 & 32 \\
\hline LC08_L1TP_123032_20130901_20200912_02_T1 & 1 September 2013 & 123 & 32 \\
\hline LC08_L1TP_123032_20131003_20200913_02_T1 & 3 October 2013 & 123 & 32 \\
\hline LC08_L1TP_123032_20131104_20200912_02_T1 & 4 November 2013 & 123 & 32 \\
\hline LC08_L1TP_123032_20131120_20200912_02_T1 & 20 November 2013 & 123 & 32 \\
\hline LC08_L1TP_123032_20131206_20200912_02_T1 & 6 December 2013 & 123 & 32 \\
\hline LC08_L1TP_123032_20131222_20200912_02_T1 & 22 December 2013 & 123 & 32 \\
\hline LC08_L1TP_123032_20140208_20200912_02_T1 & 8 February 2014 & 123 & 32 \\
\hline LC08_L1TP_123032_20140413_20200911_02_T1 & 13 April 2014 & 123 & 32 \\
\hline LC08_L1TP_123032_20140429_20200911_02_T1 & 29 April 2014 & 123 & 32 \\
\hline LC08_L1TP_123032_20140515_20200911_02_T1 & 15 May 2014 & 123 & 32 \\
\hline
\end{tabular}


Table A1. Cont.

\begin{tabular}{|c|c|c|c|}
\hline Image Id & Date & Path & Row \\
\hline LC08_L1TP_123032_20140718_20200911_02_T1 & 18 July 2014 & 123 & 32 \\
\hline LC08_L1TP_123032_20140803_20200911_02_T1 & 3 August 2014 & 123 & 32 \\
\hline LC08_L1TP_123032_20140819_20200911_02_T1 & 19 August 2014 & 123 & 32 \\
\hline LC08_L1TP_123032_20140904_20200911_02_T1 & 4 September 2014 & 123 & 32 \\
\hline LC08_L1TP_123032_20140920_20200910_02_T1 & 20 September 2014 & 123 & 32 \\
\hline LC08_L1TP_123032_20141006_20200910_02_T1 & 6 October 2014 & 123 & 32 \\
\hline LC08_L1TP_123032_20141225_20200910_02_T1 & 25 December 2014 & 123 & 32 \\
\hline LC08_L1TP_123032_20150110_20200910_02_T1 & 10 January 2015 & 123 & 32 \\
\hline LC08_L1TP_123032_20150315_20200909_02_T1 & 15 March 2015 & 123 & 32 \\
\hline LC08_L1TP_123032_20150416_20200909_02_T1 & 16 April 2015 & 123 & 32 \\
\hline LC08_L1TP_123032_20150502_20200909_02_T1 & 2 May 2015 & 123 & 32 \\
\hline LC08_L1TP_123032_20150518_20200909_02_T1 & 18 May 2015 & 123 & 32 \\
\hline LC08_L1TP_123032_20150705_20200909_02_T1 & 5 July 2015 & 123 & 32 \\
\hline LC08_L1TP_123032_20150806_20200908_02_T1 & 6 August 2015 & 123 & 32 \\
\hline LC08_L1TP_123032_20150822_20200908_02_T1 & 22 August 2015 & 123 & 32 \\
\hline LC08_L1TP_123032_20150907_20200908_02_T1 & 7 September 2015 & 123 & 32 \\
\hline LC08_L1TP_123032_20150923_20200908_02_T1 & 23 September 2015 & 123 & 32 \\
\hline LC08_L1TP_123032_20151009_20200908_02_T1 & 9 October 2015 & 123 & 32 \\
\hline LC08_L1TP_123032_20151126_20200908_02_T1 & 26 November 2015 & 123 & 32 \\
\hline LC08_L1TP_123032_20151228_20200908_02_T1 & 28 December 2015 & 123 & 32 \\
\hline LC08_L1TP_123032_20160129_20200907_02_T1 & 29 January 2016 & 123 & 32 \\
\hline LC08_L1TP_123032_20160214_20200907_02_T1 & 14 February 2016 & 123 & 32 \\
\hline LC08_L1TP_123032_20160301_20200907_02_T1 & 1 March 2016 & 123 & 32 \\
\hline LC08_L1TP_123032_20160317_20200907_02_T1 & 17 March 2016 & 123 & 32 \\
\hline LC08_L1TP_123032_20160402_20200907_02_T1 & 2 April 2016 & 123 & 32 \\
\hline LC08_L1TP_123032_20160418_20200907_02_T1 & 18 April 2016 & 123 & 32 \\
\hline LC08_L1TP_123032_20160504_20200907_02_T1 & 4 May 2016 & 123 & 32 \\
\hline LC08_L1TP_123032_20160520_20200907_02_T1 & 20 May 2016 & 123 & 32 \\
\hline LC08_L1TP_123032_20160605_20200906_02_T1 & 5 June 2016 & 123 & 32 \\
\hline LC08_L1TP_123032_20160621_20200906_02_T1 & 21 June 2016 & 123 & 32 \\
\hline LC08_L1TP_123032_20160707_20200906_02_T1 & 7 July 2016 & 123 & 32 \\
\hline LC08_L1TP_123032_20160808_20200906_02_T1 & 8 August 2016 & 123 & 32 \\
\hline LC08_L1TP_123032_20160909_20200906_02_T1 & 9 September 2016 & 123 & 32 \\
\hline LC08_L1TP_123032_20161011_20200905_02_T1 & 11 October 2016 & 123 & 32 \\
\hline LC08_L1TP_123032_20161112_20200905_02_T1 & 12 November 2016 & 123 & 32 \\
\hline LC08_L1TP_123032_20161128_20200905_02_T1 & 28 November 2016 & 123 & 32 \\
\hline LC08_L1TP_123032_20161214_20200905_02_T1 & 14 December 2016 & 123 & 32 \\
\hline LC08_L1TP_123032_20170131_20200905_02_T1 & 31 January 2017 & 123 & 32 \\
\hline LC08_L1TP_123032_20170304_20200905_02_T1 & 4 March 2017 & 123 & 32 \\
\hline LC08_L1TP_123032_20170405_20200904_02_T1 & 5 April 2017 & 123 & 32 \\
\hline LC08_L1TP_123032_20170421_20200904_02_T1 & 21 April 2017 & 123 & 32 \\
\hline LC08_L1TP_123032_20170507_20200904_02_T1 & 7 May 2017 & 123 & 32 \\
\hline LC08_L1TP_123032_20170523_20200903_02_T1 & 23 May 2017 & 123 & 32 \\
\hline LC08_L1TP_123032_20170710_20200903_02_T1 & 10 July 2017 & 123 & 32 \\
\hline LC08_L1TP_123032_20170912_20200903_02_T1 & 12 September 2017 & 123 & 32 \\
\hline LC08_L1TP_123032_20170928_20200903_02_T1 & 28 September 2017 & 123 & 32 \\
\hline LC08_L1TP_123032_20171030_20200902_02_T1 & 30 October 2017 & 123 & 32 \\
\hline LC08_L1TP_123032_20171115_20200902_02_T1 & 15 November 2017 & 123 & 32 \\
\hline LC08_L1TP_123032_20171201_20200902_02_T1 & 1 December 2017 & 123 & 32 \\
\hline LC08_L1TP_123032_20171217_20200902_02_T1 & 17 December 2017 & 123 & 32 \\
\hline LC08_L1TP_123032_20180102_20200902_02_T1 & 2 January 2018 & 123 & 32 \\
\hline LC08_L1TP_123032_20180203_20200902_02_T1 & 3 February 2018 & 123 & 32 \\
\hline LC08_L1TP_123032_20180408_20201015_02_T1 & 8 April 2018 & 123 & 32 \\
\hline LC08_L1TP_123032_20180627_20200831_02_T1 & 27 June 2018 & 123 & 32 \\
\hline LC08_L1TP_123032_20181001_20200830_02_T1 & 1 October 2018 & 123 & 32 \\
\hline LC08_L1TP_123032_20181017_20200830_02_T1 & 17 October 2018 & 123 & 32 \\
\hline LC08_L1TP_123032_20181102_20200830_02_T1 & 2 November 2018 & 123 & 32 \\
\hline LC08_L1TP_123032_20181118_20200830_02_T1 & 18 November 2018 & 123 & 32 \\
\hline
\end{tabular}


Table A1. Cont.

\begin{tabular}{lrrr}
\hline Image Id & Date & Path & Row \\
\hline LC08_L1TP_123032_20181204_20200830_02_T1 & 4 December 2018 & 123 & 32 \\
LC08_L1TP_123032_20190121_20200829_02_T1 & 21 January 2019 & 123 & 32 \\
LC08_L1TP_123032_20190326_20200829_02_T1 & 26 March 2019 & 123 & 32 \\
LC08_L1TP_123032_20190411_20200829_02_T1 & 11 April 2019 & 123 & 32 \\
LC08_L1TP_123032_20190513_20200828_02_T1 & 13 May 2019 & 123 & 32 \\
LC08_L1TP_123032_20190529_20200828_02_T1 & 29 May 2019 & 123 & 32 \\
LC08_L1TP_123032_20190614_20200828_02_T1 & 14 June 2019 & 123 & 32 \\
LC08_L1TP_123032_20190630_20200827_02_T1 & 30 June 2019 & 123 & 32 \\
LC08_L1TP_123032_20190817_20200827_02_T1 & 17 August 2019 & 123 & 32 \\
LC08_L1TP_123032_20190902_20200826_02_T1 & 2 September 2019 & 123 & 32 \\
LC08_L1TP_123032_20190918_20200826_02_T1 & 18 September 2019 & 123 & 32 \\
LC08_L1TP_123032_20191020_20200825_02_T1 & 20 October 2019 & 123 & 32 \\
LC08_L1TP_123032_20191105_20200825_02_T1 & 5 November 2019 & 123 & 32 \\
LC08_L1TP_123032_20191207_20200824_02_T1 & 7 December 2019 & 123 & 32 \\
LC08_L1TP_123032_20191223_20200824_02_T1 & 23 December 2019 & 123 & 32 \\
LC08_L1TP_123032_20200108_20200823_02_T1 & 8 January 2020 & 123 & 32 \\
LC08_L1TP_123032_20200124_20200823_02_T1 & 24 January 2020 & 123 & 32 \\
LC08_L1TP_123032_20200209_20200823_02_T1 & 9 February 2020 & 123 & 32 \\
LC08_L1TP_123032_20200312_20200822_02_T1 & 12 March 2020 & 123 & 32 \\
LC08_L1TP_123032_20200328_20200822_02_T1 & 28 March 2020 & 123 & 32 \\
LC08_L1TP_123032_20200413_20200822_02_T1 & 13 April 2020 & 123 & 32 \\
LC08_L1TP_123032_20200429_20200820_02_T1 & 29 April 2020 & 123 & 32 \\
LC08_L1TP_123032_20200531_20200820_02_T1 & 31 May 2020 & 123 & 32 \\
LC08_L1TP_123032_20200803_20200914_02_T1 & 3 August 2020 & 123 & 32 \\
LC08_L1TP_123032_20200904_20200918_02_T1 & 4 September 2020 & 123 & 32 \\
LC08_L1TP_123032_20200920_20201005_02_T1 & 20 September 2020 & 123 & 32 \\
LC08_L1TP_123032_20201006_20201016_02_T1 & 6 October 2020 & 123 & 32 \\
LC08_L1TP_123032_20201022_20201105_02_T1 & 22 October 2020 & 123 & 32 \\
LC08_L1TP_123032_20201123_20210315_02_T1 & 23 November 2020 & 123 & 32 \\
LC08_L1TP_123032_20201225_20210310_02_T1 & 25 December 2020 & 123 & 32 \\
\hline
\end{tabular}

\section{References}

1. Choumert, J.; Salanié, J. Provision of urban green spaces: Some insights from economics. Landsc. Res. 2008, 33, 331-345. [CrossRef]

2. Beninde, J.; Veith, M.; Hochkirch, A. Biodiversity in cities needs space: A meta-analysis of factors determining intra-urban biodiversity variation. Ecol. Lett. 2015, 18, 581-592. [CrossRef]

3. Jaafari, S.; Shabani, A.A.; Moeinaddini, M.; Danehkar, A.; Sakieh, Y. Applying landscape metrics and structural equation modeling to predict the effect of urban green space on air pollution and respiratory mortality in Tehran. Environ. Monit. Assess. 2020, 192, 1-15. [CrossRef] [PubMed]

4. Kadaverugu, A.; Rao, C.N.; Viswanadh, G.K. Quantification of flood mitigation services by urban green spaces using InVEST model: A case study of Hyderabad city, India. Model. Earth Syst. Environ. 2021, 7, 589-602. [CrossRef]

5. Callaghan, A.; McCombe, G.; Harrold, A.; McMeel, C.; Mills, G.; Moore-Cherry, N.; Cullen, W. The impact of green spaces on mental health in urban settings: A scoping review. J. Ment. Health 2021, 30, 179-193. [CrossRef] [PubMed]

6. World Health Organization. Urban Green Spaces and Health: A Review of Evidence; World Health Organization: Copenhagen, Denmark, 2016.

7. Taha, H.; Akbari, H.; Rosenfeld, A.; Huang, J. Residential cooling loads and the urban heat island-The effects of albedo. Build. Environ. 1988, 23, 271-283. [CrossRef]

8. Zhao, L.; Oleson, K.; Bou-Zeid, E.; Krayenhoff, E.S.; Bray, A.; Zhu, Q.; Zheng, Z.; Chen, C.; Oppenheimer, M. Global multi-model projections of local urban climates. Nat. Clim. Chang. 2021, 11, 152-157. [CrossRef]

9. Rahman, M.A.; Armson, D.; Ennos, A.R. A comparison of the growth and cooling effectiveness of five commonly planted urban tree species. Urban Ecosyst. 2015, 18, 371-389. [CrossRef]

10. Konarska, J.; Uddling, J.; Holmer, B.; Lutz, M.; Lindberg, F.; Pleijel, H.; Thorsson, S. Transpiration of urban trees and its cooling effect in a high latitude city. Int. J. Biometeorol. 2016, 60, 159-172. [CrossRef]

11. Chen, X.; Zhao, P.; Hu, Y.; Ouyang, L.; Zhu, L.; Ni, G. Canopy transpiration and its cooling effect of three urban tree species in a subtropical city-Guangzhou, China. Urban For. Urban Green. 2019, 43, 126368. [CrossRef]

12. Shekhar, S.; Aryal, J. Role of geospatial technology in understanding urban green space of Kalaburagi city for sustainable planning. Urban For. Urban Green. 2019, 46, 126450. [CrossRef] 
13. Yu, Z.; Guo, X.; Zeng, Y.; Koga, M.; Vejre, H. Variations in land surface temperature and cooling efficiency of green space in rapid urbanization: The case of Fuzhou city, China. Urban For. Urban Green. 2018, 29, 113-121. [CrossRef]

14. Zhao, J.; Zhao, X.; Liang, S.; Zhou, T.; Du, X.; Xu, P.; Wu, D. Assessing the thermal contributions of urban land cover types. Landsc. Urban Plan. 2020, 204, 103927. [CrossRef]

15. Peng, J.; Dan, Y.; Qiao, R.; Liu, Y.; Dong, J.; Wu, J. How to quantify the cooling effect of urban parks? Linking maximum and accumulation perspectives. Remote. Sens. Environ. 2021, 252, 112135. [CrossRef]

16. Feyisa, G.L.; Dons, K.; Meilby, H. Efficiency of parks in mitigating urban heat island effect: An example from Addis Ababa. Landsc. Urban Plan. 2014, 123, 87-95. [CrossRef]

17. Shah, A.; Garg, A.; Mishra, V. Quantifying the local cooling effects of urban green spaces: Evidence from Bengaluru, India. Landsc. Urban Plan. 2021, 209, 104043. [CrossRef]

18. Tan, Z.; Lau, K.K.-L.; Ng, E.Y.Y. Urban tree design approaches for mitigating daytime urban heat island effects in a high-density urban environment. Energy Build. 2016, 114, 265-274. [CrossRef]

19. Tsoka, S.; Leduc, T.; Rodler, A. Assessing the effects of urban street trees on building cooling energy needs: The role of foliage density and planting pattern. Sustain. Cities Soc. 2021, 65, 102633. [CrossRef]

20. Speak, A.; Montagnani, L.; Wellstein, C.; Zerbe, S. The influence of tree traits on urban ground surface shade cooling. Landsc. Urban Plan. 2020, 197, 103748. [CrossRef]

21. Thomey, M.L.; Collins, S.; Vargas, R.; Johnson, J.E.; Brown, R.F.; Natvig, D.O.; Friggens, M.T. Effect of precipitation variability on net primary production and soil respiration in a Chihuahuan Desert grassland. Glob. Chang. Biol. 2010, 17, 1505-1515. [CrossRef]

22. Abel, C.; Horion, S.; Tagesson, T.; De Keersmaecker, W.; Seddon, A.W.; Abdi, A.M.; Fensholt, R. The human-environment nexus and vegetation-rainfall sensitivity in tropical drylands. Nat. Sustain. 2021, 4, 25-32. [CrossRef]

23. He, B.; Wang, S.; Guo, L.; Wu, X. Aridity change and its correlation with greening over drylands. Agric. For. Meteorol. 2019, 278, 107663. [CrossRef]

24. Sanchez-Mejia, Z.M.; Papuga, S.A.; Swetish, J.B.; van Leeuwen, W.; Szutu, D.; Hartfield, K. Quantifying the influence of deep soil moisture on ecosystem albedo: The role of vegetation. Water Resour. Res. 2014, 50, 4038-4053. [CrossRef]

25. Li, Y.; Zhao, M.; Mote, S.; Mu, Q.; Kalnay, E.; Li, S. Local cooling and warming effects of forests based on satellite observations Nat. Commun. 2015, 6, 6603. [CrossRef]

26. Fan, P.; Xu, L.; Yue, W.; Chen, J. Accessibility of public urban green space in an urban periphery: The case of Shanghai. Landsc. Urban Plan. 2017, 165, 177-192. [CrossRef]

27. Dinda, S.; Das Chatterjee, N.; Ghosh, S. An integrated simulation approach to the assessment of urban growth pattern and loss in urban green space in Kolkata, India: A GIS-based analysis. Ecol. Indic. 2021, 121, 107178. [CrossRef]

28. Banskota, A.; Kayastha, N.; Falkowski, M.J.; Wulder, M.; Froese, R.E.; White, J. Forest Monitoring Using Landsat Time Series Data: A Review. Can. J. Remote. Sens. 2014, 40, 362-384. [CrossRef]

29. Li, F.; Li, F.; Li, S.; Long, Y. Deciphering the recreational use of urban parks: Experiments using multi-source big data for all Chinese cities. Sci. Total Environ. 2020, 701, 134896. [CrossRef]

30. Li, W.; Ouyang, Z.; Meng, X.; Wang, X. Plant species composition in relation to green cover configuration and function of urban parks in Beijing, China. Ecol. Res. 2006, 21, 221-237. [CrossRef]

31. Gorelick, N.; Hancher, M.; Dixon, M.; Ilyushchenko, S.; Thau, D.; Moore, R. Google Earth Engine: Planetary-scale geospatial analysis for everyone. Remote. Sens. Environ. 2017, 202, 18-27. [CrossRef]

32. Masek, J.; Vermote, E.; Saleous, N.; Wolfe, R.; Hall, F.; Huemmrich, K.; Gao, F.; Kutler, J.; Lim, T.-K. A Landsat Surface Reflectance Dataset for North America, 1990-2000. IEEE Geosci. Remote. Sens. Lett. 2006, 3, 68-72. [CrossRef]

33. Vermote, E.; Justice, C.; Claverie, M.; Franch, B. Preliminary analysis of the performance of the Landsat $8 /$ OLI land surface reflectance product. Remote. Sens. Environ. 2016, 185, 46-56. [CrossRef] [PubMed]

34. Foga, S.; Scaramuzza, P.L.; Guo, S.; Zhu, Z.; Dilley, R.D., Jr.; Beckmann, T.; Schmidt, G.L.; Dwyer, J.L.; Hughes, M.J.; Laue, B. Cloud detection algorithm comparison and validation for operational Landsat data products. Remote Sens. Environ. 2017, 194, 379-390. [CrossRef]

35. Zhu, Z.; Fu, Y.; Woodcock, C.E.; Olofsson, P.; Vogelmann, J.; Holden, C.; Wang, M.; Dai, S.; Yu, Y. Including land cover change in analysis of greenness trends using all available Landsat 5, 7, and 8 images: A case study from Guangzhou, China (2000-2014). Remote. Sens. Environ. 2016, 185, 243-257. [CrossRef]

36. Roy, D.; Kovalskyy, V.; Zhang, H.; Vermote, E.; Yan, L.; Kumar, S.S.; Egorov, A. Characterization of Landsat-7 to Landsat-8 reflective wavelength and normalized difference vegetation index continuity. Remote. Sens. Environ. 2016, 185, 57-70. [CrossRef] [PubMed]

37. Fassnacht, F.E.; Schiller, C.; Kattenborn, T.; Zhao, X.; Qu, J. A Landsat-based vegetation trend product of the Tibetan Plateau for the time-period 1990-2018. Sci. Data 2019, 6, 1-11. [CrossRef] [PubMed]

38. Anderson, K.; Fawcett, D.; Cugulliere, A.; Benford, S.; Jones, D.; Leng, R. Vegetation expansion in the subnival Hindu Kush Himalaya. Glob. Chang. Biol. 2020, 26, 1608-1625. [CrossRef]

39. Jiménez-Muñoz, J.C.; Sobrino, J.A. A generalized single-channel method for retrieving land surface temperature from remote sensing data. J. Geophys. Res. Space Phys. 2003, 108, 108. [CrossRef]

40. Malakar, N.K.; Hulley, G.C.; Hook, S.J.; Laraby, K.; Cook, M.; Schott, J.R. An Operational Land Surface Temperature Product for Landsat Thermal Data: Methodology and Validation. IEEE Trans. Geosci. Remote. Sens. 2018, 56, 5717-5735. [CrossRef] 
41. Jiménez-Muñoz, J.C.; Cristóbal, J.; Sobrino, J.A.; Soria, G.; Ninyerola, M.; Pons, X. Revision of the Single-Channel Algorithm for Land Surface Temperature Retrieval From Landsat Thermal-Infrared Data. IEEE Trans. Geosci. Remote. Sens. 2009, 47, 339-349. [CrossRef]

42. Lyapustin, A.; Wang, Y. MCD19A2 MODIS/Terra+Aqua Land Aerosol Optical Depth Daily L2G Global 1 km SIN Grid V006. NASA EOSDIS Land Processes DAAC 2018. Available online: https:/ / doi.org/10.5067/MODIS/MCD19A2.006 (accessed on 24 June 2021).

43. Kalnay, E.; Kanamitsu, M.; Kistler, R.; Collins, W.; Deaven, D.; Gandin, L.; Iredell, M.; Saha, S.; White, G.; Woollen, J. The NCEP/NCAR 40-year reanalysis project. Bull. Am. Meteorol. Soc. 1996, 77, 437-472. [CrossRef]

44. Ermida, S.L.; Soares, P.; Mantas, V.; Göttsche, F.-M.; Trigo, I.F. Google Earth Engine Open-Source Code for Land Surface Temperature Estimation from the Landsat Series. Remote. Sens. 2020, 12, 1471. [CrossRef]

45. Davies, L.; Gather, U. The identification of multiple outliers. J. Am. Stat. Assoc. 1993, 88, 782-792. [CrossRef]

46. Duan, S.-B.; Li, Z.-L.; Li, H.; Göttsche, F.-M.; Wu, H.; Zhao, W.; Leng, P.; Zhang, X.; Coll, C. Validation of Collection 6 MODIS land surface temperature product using in situ measurements. Remote. Sens. Environ. 2019, 225, 16-29. [CrossRef]

47. Mu, Q.; Zhao, M.; Running, S.W. Improvements to a MODIS global terrestrial evapotranspiration algorithm. Remote. Sens. Environ. 2011, 115, 1781-1800. [CrossRef]

48. Monteith, J.L. Evaporation and environment. In Symposia of the Society for Experimental Biology; Cambridge University Press: Cambridge, UK, 1965; pp. 205-234.

49. Saha, S.; Moorthi, S.; Wu, X.; Wang, J.; Nadiga, S.; Tripp, P.; Behringer, D.; Hou, Y.-T.; Chuang, H.-Y.; Iredell, M.; et al. NCEP Climate Forecast System Version 2 (CFSv2) 6-hourly Products. Res. Data Arch. Natl. Center Atmos. Res. Comput. Inf. Syst. Lab. 2011, 10, D61C1TXF. [CrossRef]

50. Buchhorn, M.; Lesiv, M.; Tsendbazar, N.-E.; Herold, M.; Bertels, L.; Smets, B. Copernicus Global Land Cover Layers-Collection. Remote. Sens. 2020, 12, 1044. [CrossRef]

51. Liang, S. Narrowband to broadband conversions of land surface albedo I: Algorithms. Remote. Sens. Environ. 2001, 76, 213-238. [CrossRef]

52. Anees, A.; Aryal, J.; O’Reilly, M.; Gale, T. A Relative Density Ratio-Based Framework for Detection of Land Cover Changes in MODIS NDVI Time Series. IEEE J. Sel. Top. Appl. Earth Obs. Remote. Sens. 2015, 9, 3359-3371. [CrossRef]

53. Cleveland, R.B. STL: A seasonal-trend decomposition procedure based on loess. J. Off. Stat. 1990, 6, 3-73.

54. Muggeo, V.M.R. Estimating regression models with unknown break-points. Stat. Med. 2003, 22, 3055-3071. [CrossRef]

55. Zhu, Z.; Piao, S.; Myneni, R.B.; Huang, M.; Zeng, Z.; Canadell, J.G.; Ciais, P.; Sitch, S.; Friedlingstein, P.; Arneth, A.; et al. Greening of the Earth and its drivers. Nat. Clim. Chang. 2016, 6, 791-795. [CrossRef]

56. Seddon, A.; Macias-Fauria, M.; Long, P.R.; Benz, D.; Willis, K. Sensitivity of global terrestrial ecosystems to climate variability. Nat. Cell Biol. 2016, 531, 229-232. [CrossRef]

57. Zhao, S.; Liu, S.; Zhou, D. Prevalent vegetation growth enhancement in urban environment. Proc. Natl. Acad. Sci. USA 2016, 113, 6313-6318. [CrossRef]

58. Zhou, D.; Zhao, S.; Zhang, L.; Liu, S. Remotely sensed assessment of urbanization effects on vegetation phenology in China's 32 major cities. Remote Sens. Environ. 2016, 176, 272-281. [CrossRef]

59. Popek, R.; Przybysz, A.; Gawrońska, H.; Klamkowski, K.; Gawroński, S.W. Impact of particulate matter accumulation on the photosynthetic apparatus of roadside woody plants growing in the urban conditions. Ecotoxicol. Environ. Saf. 2018, 163, 56-62. [CrossRef] [PubMed]

60. Yang, J.; McBride, J.; Zhou, J.; Sun, Z. The urban forest in Beijing and its role in air pollution reduction. Urban For. Urban Green. 2005, 3, 65-78. [CrossRef]

61. Ow, L.F.; Ghosh, S.; Yusof, M.L.M. Growth of Samanea saman: Estimated cooling potential of this tree in an urban environment. Urban For. Urban Green. 2019, 41, 264-271. [CrossRef]

62. Rahman, M.A.; Moser, A.; Rötzer, T.; Pauleit, S. Comparing the transpirational and shading effects of two contrasting urban tree species. Urban Ecosyst. 2019, 22, 683-697. [CrossRef]

63. Zou, Z.; Yang, Y.; Qiu, G.Y. Quantifying the Evapotranspiration Rate and Its Cooling Effects of Urban Hedges Based on Three-Temperature Model and Infrared Remote Sensing. Remote. Sens. 2019, 11, 202. [CrossRef]

64. Yin, J.; Wu, X.; Shen, M.; Zhang, X.; Zhu, C.; Xiang, H.; Shi, C.; Guo, Z.; Li, C. Impact of urban greenspace spatial pattern on land surface temperature: A case study in Beijing metropolitan area, China. Landsc. Ecol. 2019, 34, 2949-2961. [CrossRef]

65. Qiu, K.; Jia, B. The roles of landscape both inside the park and the surroundings in park cooling effect. Sustain. Cities Soc. 2020, 52, 101864. [CrossRef]

66. Gunawardena, K.; Wells, M.; Kershaw, T. Utilising green and bluespace to mitigate urban heat island intensity. Sci. Total. Environ. 2017, 584-585, 1040-1055. [CrossRef] [PubMed]

67. Azevedo, J.A.; Chapman, L.; Muller, C.L. Quantifying the Daytime and Night-Time Urban Heat Island in Birmingham, UK: A Comparison of Satellite Derived Land Surface Temperature and High Resolution Air Temperature Observations. Remote. Sens. 2016, 8, 153. [CrossRef] 